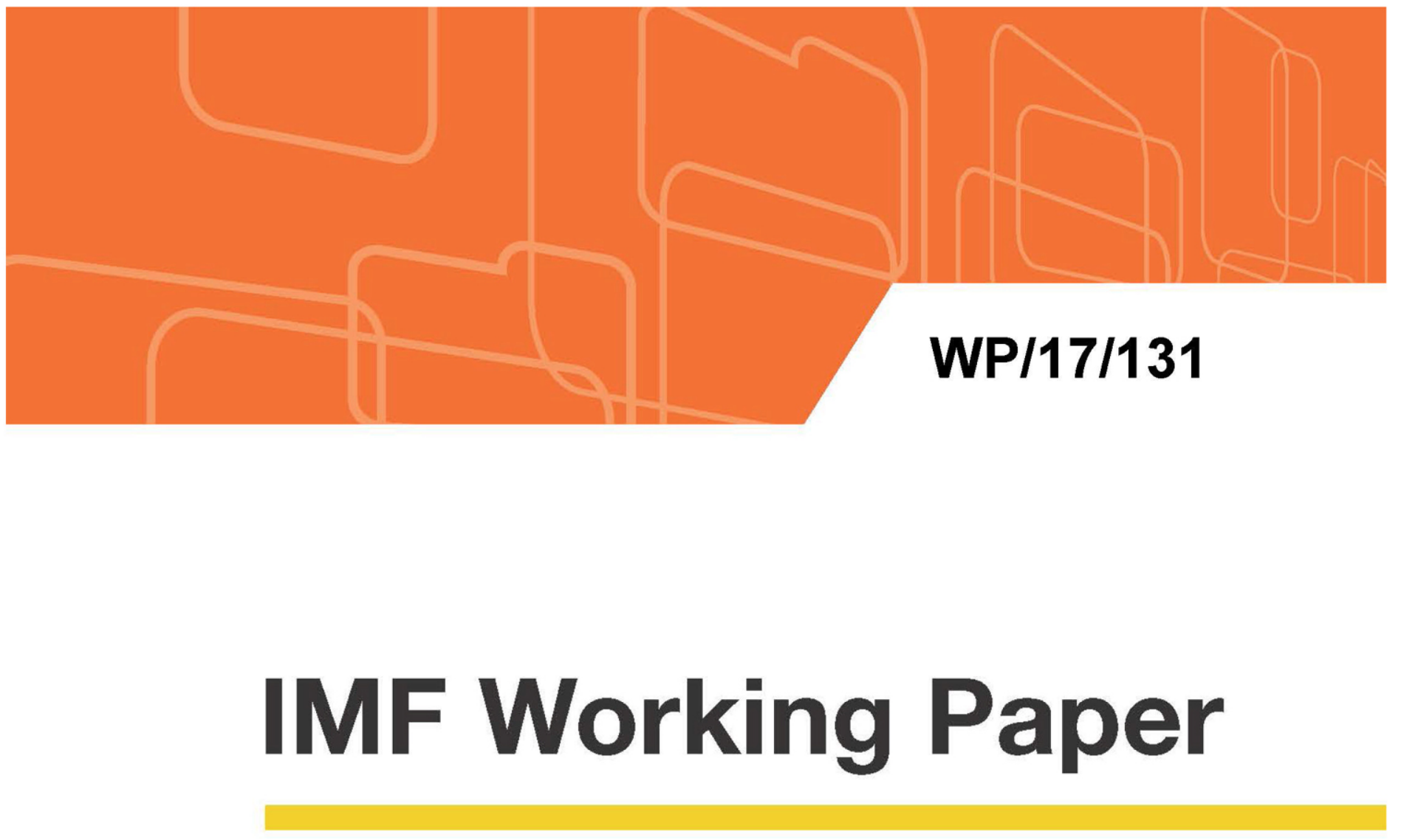

\title{
Financial Disruptions and the Cyclical Upgrading of Labor
}

by Brendan Epstein, Alan Finkelstein Shapiro and Andrés González Gómez

IMF Working Papers describe research in progress by the author(s) and are published to elicit comments and to encourage debate. The views expressed in IMF Working Papers are those of the author(s) and do not necessarily represent the views of the IMF, its Executive Board, or IMF management. 


\section{WP/17/131}

\section{IMF Working Paper}

\section{Financial Disruptions and the Cyclical Upgrading of Labor}

by Brendan Epstein, Alan Finkelstein Shapiro and Andrés González Gómez

IMF Working Papers describe research in progress by the author(s) and are published to elicit comments and to encourage debate. The views expressed in IMF Working Papers are those of the author(s) and do not necessarily represent the views of the IMF, its Executive Board, or IMF management. 


\title{
IMF Working Paper
}

Institute for Capacity Development

\section{Financial Disruptions and the Cyclical Upgrading of Labor}

\author{
Prepared by Brendan Epstein, Alan Finkelstein Shapiro and Andrés González Gómez
}

\author{
Authorized for distribution by Charlie Kramer
}

June 2017

\begin{abstract}
IMF Working Papers describe research in progress by the author(s) and are published to elicit comments and to encourage debate. The views expressed in IMF Working Papers are those of the author(s) and do not necessarily represent the views of the IMF, its Executive Board, or IMF management.
\end{abstract}

\begin{abstract}
Amid total factor productivity (TFP) shocks job-to-job flows amplify the volatility of unemployment, but the aggregate implications of job-to-job flows amid financial shocks are less understood. To develop such understanding, we model a general equilibrium labor-search framework that incorporates on-the-job (OTJ) search and distinctly accounts for the differential impact of TFP and financial shocks. Surprisingly, we find that the interaction of OTJ search with financial shocks is sufficiently different from its interaction with TFP shocks so that, under standard calibrations, our model generates aggregate dynamics exceedingly in line with the behavior of key U.S. macro data across several decades and in the wake of the Global Financial Crisis as well. Importantly, as in the data, the model yields relatively high volatilities of consumption, labor income, and unemployment. As such, our work contributes to resolving two limitations of current general equilibrium labor-search theory: under standard calibrations models without OTJ search generate implausibly low unemployment volatility, while models with OTJ search generate unemployment volatility loser to the data but at the expense of implausibly low consumption and labor-income volatility.
\end{abstract}

JEL Classification Numbers: E24, E32, E44

Keywords: Business cycles, financial frictions, labor search frictions, on-the-job search.

Author's E-Mail Address: brendan.epstein@frb.gov, Alan.Finkelstein\_Shapiro@tufts.edu, agonzalez@imf.org 


\section{Contents}

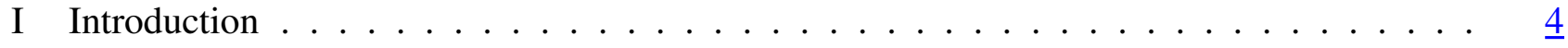

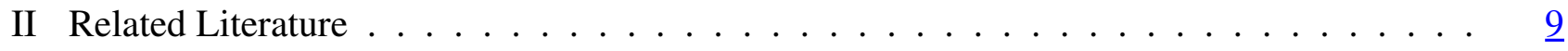

III The Model . . . . . . . . . . . . . . . . . . . . . . . . . . . . . . . . . 11

A Households ........................ . . $\ldots \ldots$

B Production ....................... 14

C Wage Determination . . . . . . . . . . . . . . . . . 17

D Closing the Model and Competitive Equilibrium . . . . . . . . . . . 18

IV Background for Simulation Analysis . . . . . . . . . . . . . . . . . . . . 19

A Stochastic Processes . . . . . . . . . . . . . . . . . . . . 19

B Functional Forms and Parameter Selection . . . . . . . . . . . $\underline{22}$

$\mathrm{V}$ Results .......................... $\underline{25}$

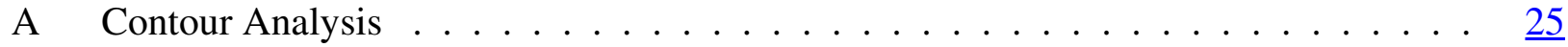

B Statistical Analysis ...................

VI Driving Forces Behind Benchmark Results . . . . . . . . . . . . . . . . . $\underline{33}$

A Impulse Response Function Analysis . . . . . . . . . . . . . . . . . $\underline{33}$

$1 \quad$ Negative Aggregate TFP Shock . . . . . . . . . . . . . . $\underline{33}$

2 Negative Aggregate Financial Shock . . . . . . . . . . . . . $\underline{35}$

B Wages and Consumption: TFP v. Financial Shocks . . . . . . . . . . . $\underline{37}$

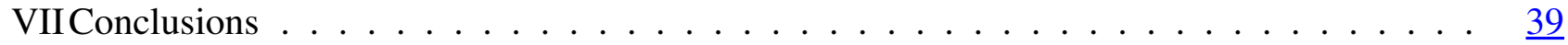




\section{List of Tables}

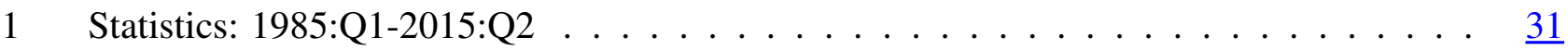

2 Additional statistics: 1990:Q2-2013:Q3 and 2001:Q1-2015:Q2 . . . . . . . $\underline{32}$

\section{List of Figures}

1 Cyclical Dynamics of the Unemployment Rate, Net Quits, Private Consumption and

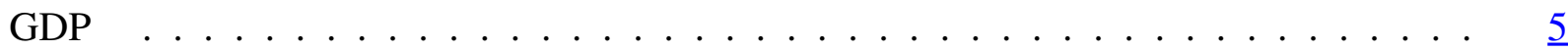

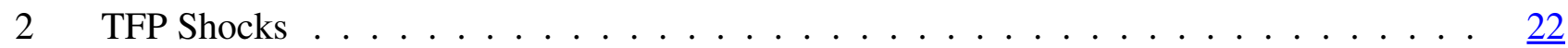

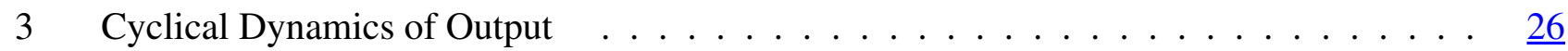

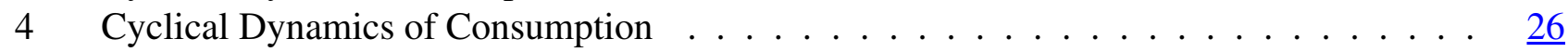

5 Cyclical Dynamics of Investment . . . . . . . . . . . . . . . . . . . $\underline{27}$

6 Cyclical Dynamics of Unemployment . . . . . . . . . . . . . . . . . $\underline{28}$

7 Cyclical Dynamics of the $v / u \ldots \ldots \ldots \ldots \ldots \ldots$

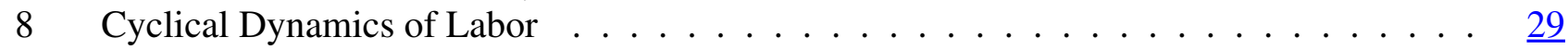

9 Cyclical Dynamics of Net Quits . . . . . . . . . . . . . . . . . $\underline{30}$

10 Impulse Response Functions to a 1-standard Deviation Negative TFP Shock. . . . . . . . $\underline{34}$

11 Impulse Response Functions to a 1-standard Deviation Negative Financial Shock. . . . . $\underline{35}$ 


\section{INTRODUCTION}

The cyclical upgrading of labor-whereby individuals transition from lower-paying jobs to higherpaying jobs—is well documented and studied (among others: McLaughlin and Bils, 2001; Barlevy, 2002; Krause and Lubik, 2006, 2010; Barnichon and Zylberbeg, 2014). Figure 1 highlights for the period 1990:Q1-2015:Q2 some well-known stylized facts of U.S. recessions: increases in the unemployment rate; decreases in output, consumption, investment, labor income, and job-to-job flowsas proxied for by net quit rates (the ratio of total quits, net of flows from employment to out of the labor force, to total employment); and higher credit tightness. ${ }^{1}$ The extent to which the net quit rate contracted in the wake of the GFC relative to other recessions suggests a severe disruption in the ability of employed workers to transition to better paying jobs via on-the-job (OTJ) search.

The impact of productivity shocks on the canonical partial-equilibrium labor search model (Pissarides, 2000, Chapter 1), i.e., absent OTJ search, are well known: under standard calibrations, the model falls dramatically short of delivering sufficient unemployment volatility to match the data given the extent to which wages are flexible under the standard assumption of Nash bargaining (Shimer, 2005, among others). A lesser known implication, which we emphasize in our analysis, is that in a general equilibrium version of the canonical model this degree of wage flexibility can generate consumption and labor-income volatility that are quite in line with the data.

It is also well known that amid total factor productivity (TFP) shocks job-to-job flows are an important channel by which the volatility of unemployment is amplified. For instance, under standard calibrations a general equilibrium version of the canonical model that incorporates on-the-job (OTJ) search induces a substantial amount of endogenous wage rigidity, which translates into considerably higher unemployment volatility than in the absence of OTJ search (see, for instance, Krause and Lubik, 2006, 2010, among others). However, an important though lesser known implication of this wage rigidity, which we emphasize in our analysis, is that OTJ search induces implausibly low

The opinions expressed in this research are those of the authors and do not necessarily reflect the views of the Board of Governors of the Federal Reserve System or of any other person associated with the Federal Reserve System, the International Monetary Fund (IMF) or the countries the IMF represents. Any errors are our own.

${ }^{1}$ Data span in Figure 1 are limited by the availability of data on quits. Fallick and Fleischman (2004) and Nagypál (2008) show that the rate of job-to-job flows is 2 to 3 times higher compared to the rate of transitions from employment to unemployment; our data on net quits are consistent with this fact. 
consumption and labor-income volatility (intuitively, these results stem from the endogenous wage rigidity associated with the presence of OTJ search).
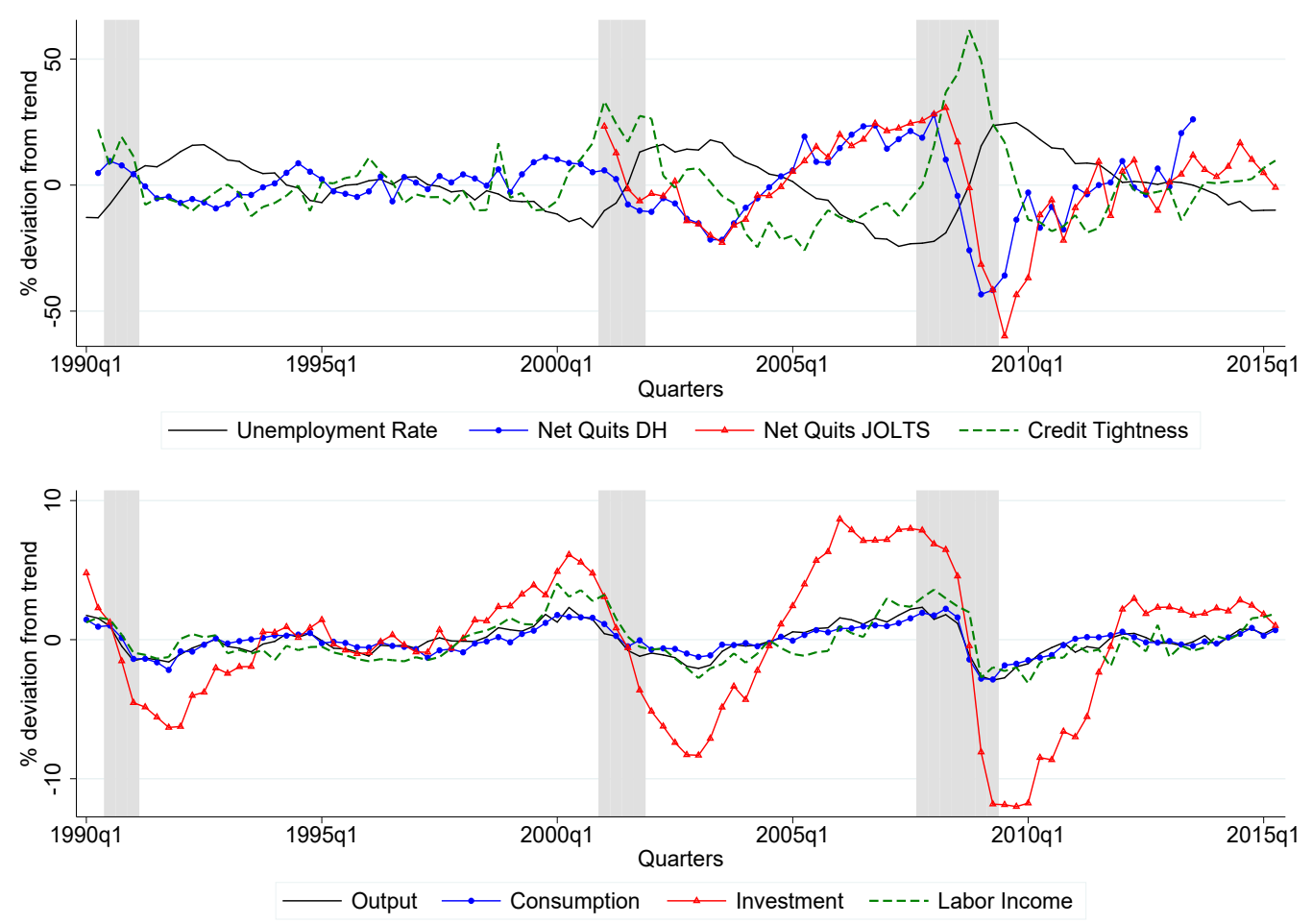

Figure 1: Cyclical Dynamics of the Unemployment Rate, Net Quits, Private Consumption and GDP

Top panel: cyclical dynamics of the unemployment rate, net quits DH (constructed using data from Davis and Haltiwanger, 2014, and data from the Current Population Survey), net quits JOLTS (constructed using data from the Bureau of Labor Statistics' Job Openings and Labor Turnover Survey and the Current Population Survey), and credit tightness. Bottom panel: cyclical dynamics of output, (private) consumption, (private) investment, and labor income (proxied for by the wage bill). Data span: 1990:Q1-2015:Q2. Recession quarters are marked in gray. All variables are in percent deviations from steady state except credit tightness, which is in percentage point deviations from steady state. ${ }^{2}$

While the aggregate implications of OTJ search amid productivity shocks are well understood, the GFC, during which job-to-job flows plummeted while credit tightness skyrocketed begs the question: What are the aggregate implications of OTJ search amid financial shocks? This question is particularly important since, as noted in Figure 1, while the GFC amplified the stylized response of key macro aggregates relative to other recessions, contractions in job-to-job flows and increases in credit tightness are a feature of earlier recessions as well.

The aim of this paper is to develop a better understanding of how job-to-job flows and financial shocks interact. Surprisingly, we find that this interaction is sufficiently distinct from that of job-tojob flows and TFP shocks that, jointly accounting for OTJ search, TFP shocks, and financial shocks 
can induce (under standard calibrations) aggregate dynamics exceedingly in line with the behavior key U.S. macro data across several decades and amid the GFC as well. In particular, accounting jointly for these variables results in high labor income volatility, and therefore high consumption volatility, side by side with high unemployment volatility. (This statement holds in absolute terms, and also when the model is compared to simpler frameworks that abstract from these joint features.) As such, our results provide a framework in which, under standard calibrations - in particular, with relatively low unemployment benefits - and in stark contrast to related literature, high unemployment volatility need not rely on an environment of relatively rigid wages.

These results hinge on a main finding of our paper: accounting for financial shocks relaxes endogenous wage rigidities associated with the presence of OTJ search without offsetting the high volatility of unemployment inherent to the presence of OTJ search. All told, our model and results are an important step forward in resolving important limitations of standard general equilibrium labor-search theory. Nonetheless, our analysis also suggests that in our framework neither financial shocks nor TFP shocks are sufficient to understand the slow recovery pace in the aftermath of the GFC, and therefore that other forces (likely related to balance-sheet repair and uncertainty, among others, which are outside of our model) are also relevant for shedding additional light on the sluggish recovery.

Our modeling framework specifically brings together the approaches in Krause and Lubik (2006, 2010) as related to frictional labor markets and OTJ search, therefore allowing for the cyclical upgrading of labor, and Jermann and Quadrini (2012) as related to financial shocks and frictions. We quantitatively assess the model's fit by constructing TFP and financial time series following the methodology of Jermann and Quadrini (2012), and feeding the resulting shocks into the model to compare how well our model-generated time series can quantitatively match their empirical U.S. counterparts. ${ }^{3}$

\footnotetext{
${ }^{3}$ Our general focus is on the volatility of the data. Therefore, we abstract from labor force participation (LFP) because in the United States: 1) at a cyclical frequency the volatility of the LFP rate pales in comparison to that of net quits; 2) furthermore, in levels, since 2000:Q1 the LFP rate has followed a broad decline whose trend appears to have been little affected by economic circumstances (Fujita, 2014, shows that since 2000 between 65 and 80 percent of the trend decline in the U.S. LFP rate owes to greater retirement). We also abstract from changes in the U.S. labor share because, based on data from Karabarbounis and Neiman (2014), which is publicly available, we find that: 1) the cyclical behavior of the labor share also pales in comparison to that of net quits; 2) since the GFC the level of the labor share decreased by less than 1 percent following a slowly declining trend pattern that started decades ago and implies a yearly decline of the labor share of roughly 0.2 percent.
} 
To better understand our findings, first consider a negative TFP shock. As noted in Krause and Lubik $(2006,2010)$, this shock triggers a large contraction in vacancy postings that induces a rise in unemployment and a long-lived contraction in job-to-job flows as the incentives for these transitions are dampened in light of the deterioration in the value of jobs to workers. While all else equal the contraction in vacancies puts downward pressure on the ratio of vacancies to job searchers on which wages are inversely related to (this ratio is reflective of workers' outside options), the large reduction in the pool of OTJ searchers puts upward pressure on this ratio resulting in relatively rigid wages compared to a framework that abstracts from OTJ search. As such, the surplus from jobs, which is among other things a function of the difference between labor productivity and wages, deteriorates substantially. Ultimately, relatively rigid wages induced by the presence of OTJ search result in a considerable increase in unemployment. However, this relative wage rigidity also results in relatively low wage and labor income volatility and ultimately anemic consumption volatility relative to the data.

Now, consider an adverse financial shock as captured by an exogenous contraction in firms' borrowing capacity. This shock tightens firms' collateral constraints, which in turn increases their collateral shadow values and adversely affects their incentive to hire workers. As such, financial shocks themselves contribute to more volatile recruiting and therefore more volatile outside options for workers compared to an environment without these shocks. The resulting fall in vacancies puts downward pressure on wages as workers' outside options fall, which lowers the value of jobs for workers and therefore of OTJ search as well. However, in stark contrast to a negative TFP shock, while financial shocks induce amplification in the volatility of unemployment, this amplification is not accompanied by relatively high wage rigidity. Instead, it is accompanied by a considerable amount of wage flexibility due to highly volatile vacancy postings. The intuition behind this result is straightforward: an adverse financial shock induces a sharp rise in firms' collateral shadow value, which implies that firms become considerably more constrained in their ability to borrow. As a result, firms' stochastic discount factors fall sharply in response to the shock, making firms skew their focus toward current economic and financial conditions, thereby causing vacancies, wages, and labor income to fall considerably. Importantly, OTJ search amplifies this mechanism without inducing the degree of endogenous wage rigidity present amid TFP shocks.

Our quantitative analysis reveals that upon joint negative shocks to TFP and financial conditions, which we show occurred not only in the wake of the GFC but also in prior U.S. recessions, the sharp 
downward pressure on wages induced by negative financial shocks countervails the upward pressure coming from developments related to OTJ search. Ultimately, in this scenario unemployment volatility is exacerbated since both the TFP shock and the financial shock amplify it, wages contract substantially (in contrast to the case in which the economy is only hit by a negative TFP shock), and this contraction leads to a substantial contraction in labor income and, therefore, consumption as well.

Of note, our model not only performs well in accounting for recessionary dynamics of key U.S. aggregate data, but also in accounting for the data's business cycle dynamics in general. As such, our main contribution to the literature lies in highlighting a simple yet relevant mechanism by which financial shocks, OTJ search, and TFP shocks are jointly critical in accounting for the dynamic behavior of fundamental U.S. macroeconomic time series over long time horizons. This contribution is in fact twofold, as it is relevant for the labor search literature in general, and also for the literature on financial imperfections. Specifically, by focusing on the importance of financial disturbances for the U.S. economy_ — which has already been stressed by Jermann and Quadrini (2012), among others — and OTJ search for unemployment volatility—which has already been stressed by Krause and Lubik (2006, 2010), among others - we reconcile two quantitative limitations of current general equilibrium theories of the labor market that emerge under standard calibrations. First, the canonical search model's inability to generate sufficiently high unemployment volatility (while indeed generating plausibly high labor income and consumption volatility). And second, the OTJ-search extended model's inability to generate sufficiently high labor income and consumption volatility (while nonetheless generating high unemployment volatility). Importantly, our results on the unemployment volatility side do not hinge on exogenously- or endogenously-determined wage rigidity nor on assuming non-standard model parameterizations.

The remainder of this paper is structured as follows. Section 2 discusses related literature and highlights in additional detail our contributions. Section 3 describes the model. Section 4 presents our methodology for generating empirically-based TFP and financial stochastic processes, our choice of functional forms, and our calibration strategy. Section 5 presents results, Section 6 presents and in-depth analysis of the driving forces underlying our results. Finally, Section 7 concludes. 


\section{RELATED Literature}

The importance of job-to-job transitions for the labor market has been widely studied (Pissarides, 1994; Krause and Lubik 2006, 2010; Nagypál, 2005, 2007, 2008; Shimer, 2006; Tasci, 2007; Menzio and Shi, 2010, 2011; Epstein, 2012; Arseneau and Epstein, 2014; Gertler, Huckfeldt, and Trigari, 2014; among others). A strand of the literature has focused on the relevance of underemploymentwhich can be a consequence of insufficient job-to-job flows-for labor market outcomes and cyclical labor market dynamics (Albrecht and Vroman, 2002; Gautier, 2002; Dolado, Jansen, and Jimeno, 2009; Chassamboulli, 2011, 2013; Ravenna and Walsh, 2012, 2014; Moscarini and Postel-Vinay, 2016; among others). In turn, the recent global financial crisis has also led to a surge in work on the consequences of imperfections in financial markets for business cycles (Jermann and Quadrini, 2012; Iacoviello, 2015; among others). This literature has expanded to analyze the implications of financial frictions for labor markets (Mehrotra and Sergeyev, 2012, 2015; Chugh, 2013; Gu, 2014; Petrosky-Nadeau, 2014; Boeri, Garibaldi, and Moen, 2015; Buera, Fattal Jaef, and Shin, 2015; and Zanetti, 2015). ${ }^{4}$ For example, Chugh (2013) focuses on the countercyclicality of the external finance premium in a context with TFP shocks and argues that, by producing endogenously rigid wages, the external finance premium helps to generate high labor market volatility. Also, Petrosky-Nadeau (2014) centers on changes in the cost of borrowing (as opposed to the ability to borrow) amid TFP shocks.

Our paper is most closely tied to Krause and Lubik (2006, 2010), Chugh (2013), and PetroskyNadeau (2014). Relative to these papers: (1) our focus is on financial frictions and shocks in a context with OTJ search and not restricted to TFP shocks alone; (2) our approach follows related literature on financial shocks and centers more on changes in firms' ability to borrow as opposed to the cost of borrowing; (3) we depart from (exogenous or endogenous) wage rigidities as the sole mechanism generating high labor market volatility; and (4) our quantitative exercise evaluates our model's ability to match key empirical data on a very broad set of macro time series using model-based constructed measures of financial shocks. Importantly, our work highlights the role of financial shocks in offsetting the endogenous wage rigidity inherent to models with OTJ search or countercyclical external finance premia in existing studies, where the latter naturally dampen the variability of wages

\footnotetext{
${ }^{4}$ For empirical evidence on financing constraints and unemployment during the crisis in the United States; see, for instance, Duygan-Bump, Levkov, and Montoriol-Garriga (2014). Related work also includes Schaal (2015), who focuses on uncertainty and unemployment rather than financial frictions, and Eckstein, Setty, and Weiss (2015).
} 
and consumption. These shocks not only generate higher labor market volatility that is closer to the data, but also improve the ability to replicate the behavior of labor income and consumption in the data, which models with wage rigidities have difficulty capturing. More broadly, relative to existing studies, our model shows that the high volatility of labor income in the data (partly a reflection of the volatility of wages) and the high volatility of unemployment can coexist.

Closest to our focus on financial shocks and employment are Monacelli, Quadrini, and Trigari (2012), Lopez and Olivella (2014), and Garín (2015), who focus on the importance of financial imperfections, their associated disturbances, and the labor market in a general equilibrium environment. Monacelli, Quadrini, and Trigari (2012) and Garín (2015) use variants of a one-sector, one-employmenttype search model and show that financial shocks contribute to larger employment fluctuations relative to models without such shocks. However, one-sector models still face limitations in generating the high degree of volatility in unemployment and aggregate market tightness (i.e., the ratio of aggregate vacancies to aggregate unemployment) in the data. Moreover, Monacelli, Quadrini, and Trigari's (2012) approach is rooted in a structural estimation of their model, which stands in contrast with the methodology we use to analyze the quantitative significance of financial shocks, where we take constructed measures of TFP and financial shocks from the data and evaluate their role in explaining actual U.S. time series.

Finally, Lopez and Olivella (2014) use a model with skilled and unskilled employment and, following Jermann and Quadrini (2012), construct time series for TFP and financial conditions to assess these shocks' role in matching the dynamics of U.S. skilled-vs.-unskilled employment. They show that a model with employment heterogeneity and financial shocks can reproduce a significant portion of unemployment fluctuations in the data. Importantly, their results hinge critically on endogenous wage rigidities at the onset of downturns. As a result, unemployment volatility increases considerably.

Our general approach to analyzing financial shocks, which also applies Jermann and Quadrini's (2012) methodology to construct TFP and financial shocks, is in line with Lopez and Olivella (2014). However, there are three main differences relative to their work. First, our focus is on a particular component of employment dynamics - mainly job-to-job transitions — and how changes in job-tojob transitions interact with financial shocks in ways that quantitatively reconcile the joint dynamics 
of unemployment and macroeconomic aggregates, including consumption, amid the GFC. This differs fundamentally from analyzing skilled versus unskilled employment, where employment heterogeneity is a feature of the production technology. Second, in contrast to Lopez and Olivella (2014), our model's ability to generate sharp unemployment fluctuations consistent with the data takes place in an environment where wages and labor income are highly volatile and contract sharply in response to adverse financial shocks. In other words, the mechanism via which our model successfully generates high unemployment volatility, among other things, is fundamentally different since it does not depend on wages being partially (endogenously) rigid at the onset of downturns, and as such is more aligned with the dynamics of labor income and consumption in the data. Third, as we explain below, we apply a refinement of the methodology to extract the exogenous shocks by purging TFP shocks and financial shocks from interaction effects. This refinement contributes to a better overall fit of the model-based macro time series with the data-based macro time series, as well as a clearer characterization of the contribution of each shock to matching the data.

In sum, our work lies at the intersection of the literature on job-to-job flows and financial frictions and labor markets. While our focus on job-to-job transitions amid the GFC is similar to Moscarini and Postel-Vinay (2016), we expand the study of job-to-job flows to a business cycle environment where firms face both financial frictions and financial shocks, which are absent in Moscarini and Postel-Vinay (2016). While the fact that the inclusion of job-to-job transitions can play a powerful amplification role in the labor market is well known (Krause and Lubik, 2006, 2010), our findings suggest that OTJ search also amplifies the adverse effects of financial imperfections and the deterioration of financial conditions during the GFC, with particularly detrimental consequences for unemployment, labor income, consumption, and investment.

\section{THE MODEL}

We extend the well-known Krause and Lubik (2006, 2010) OTJ search framework by incorporating sectoral investment, collateral constraints, and aggregate financial shocks. Production involves three firms: high- $(H)$ and low-wage $(L)$ intermediate producers and a final goods firm that aggregates output from these firms. All product markets are perfectly competitive. Intermediate output firms use labor (the hiring of which involves frictions) and internally-accumulated capital to produce; these firms also borrow funds for production. Firms' borrowing is constrained by the value 
of their capital stock (Kiyotaki and Moore, 1997; Carlstrom and Fuerst, 1997; Liu, Wang, and Zha, 2013; Iacoviello, 2015). There are three agents: high-wage intermediate-goods entrepreneurs (who own $H$ firms); low-wage intermediate-goods entrepreneurs (who own $L$ firms); and a representative household (that owns the final goods aggregator). Each agent has a unit mass, and in line with related literature there is no labor force participation margin. The household receives income from employment in intermediate goods production and profits from the final goods aggregator, and the incentive for OTJ search (which is subject to resource costs) stems from one intermediate output firm paying a higher wage than the other. ${ }^{5}$

Firms' labor-hiring decisions are, among other things, an increasing function of labor productivity that, all else equal, is intuitively higher the greater the amount of capital a firm has. In turn, higher labor productivity is associated with a greater opportunity cost of having a vacant position (Pissarides, 2000, Chapter 1). We capture this intuitive context in a reduced form way by assuming that higher-paying firms have higher vacancy-posting costs than lower-paying firms, which is sufficient to deliver wage and capital usage differentials between intermediate firms, such that higher-paying firms also engage in higher capital usage (Krause and Lubik, 2006, 2010; this framework is also broadly in line with Acemoglu, 2001). Coupled with the fact that intermediate inputs are imperfectly substitutable in final goods production but workers are homogeneous, this framework is best understood as one in which intermediate producers belong to a quasi-vertical representative production process in which workers can move up the wage ladder via OTJ search.

Employment matches in the intermediate goods sector are formed via sector-specific constant-returnsto-scale matching functions that take as inputs sector-specific vacancies and searchers. $H$-sector matches are given by $m_{H, t}=m\left(v_{H, t}, u_{H, t}+s_{t} n_{L, t}\right)$, where: $v_{H}$ is sector- $H$ vacancies; $u_{H, t}$ is the measure of unemployed searching for $H$-firm employment, $s$ is endogenous OTJ search intensity (relative to unemployed search intensity, which is normalized to 1 ); and $n_{L}$ is the mass of individuals employed by firm $L$. $L$-sector matches are given by $m_{L, t}=m\left(v_{L, t}, u_{L, t}\right)$ where: $v_{L}$ is sector- $L$ vacancies and $u_{L, t}$ is the measure of unemployed searching for $L$-firm employment. Define market tightness in sector $H$ and $L$, respectively, as $\theta_{H, t} \equiv v_{H, t} /\left(u_{H, t}+s_{t} n_{L, t}\right)$ and $\theta_{L, t} \equiv v_{L, t} / u_{L, t}$. (Aggregate market tightness is defined as the ratio of aggregate vacancies to aggregate unemployment,

\footnotetext{
${ }^{5}$ As long as the surplus from each type of job is positive (which it is, given imperfect substitutability of inputs in final production), the household has an incentive to allocate unemployed search activity to both types of jobs as it quickens average transitions from unemployment to employment.
} 
which is empirically observable and we denote by $v / u$.) Then: the probability that unemployed individuals find a job in sector $j \in\{H, L\}$ is $f_{j, t}=f\left(\theta_{j, t}\right)$, where $f^{\prime}>0$; the probability that a firm-type $j$ fills a job is $q\left(\theta_{j, t}\right)$, where $q^{\prime}<0$; and the probability of a successful job-to-job transition is $s_{t} f_{H, t}$ (individuals currently employed in firm $L$ have no incentive to search for type- $L$ jobs, so they do not appear as an input in the $L$-firm matching function; we elaborate on the household's decision to allocate unemployed individuals to search for high- and low-wage jobs below). All told, the evolution of employment in sectors $H$ and $L$ satisfy, respectively,

$$
n_{H, t+1}=(1-\rho)\left(n_{H, t}+m_{H, t}\right)
$$

and

$$
n_{L, t+1}=(1-\rho)\left(n_{L, t}+m_{L, t}-\frac{s_{t} n_{L, t}}{u_{H, t}+s_{t} n_{L, t}} m_{H, t}\right),
$$

where: $n_{H}$ is the mass of individuals employed in $H$ firms; and $\rho$ is the common sectoral job destruction probability (Krause and Lubik, 2006, 2010). Total unemployment satisfies $u_{t} \equiv u_{L, t}+$ $u_{H, t}=1-n_{H, t}-n_{L, t}$. Since the household consists of a unit mass, then $u$ is also the aggregate unemployment rate.

\section{A. Households}

The household chooses consumption $c_{h, t}$, assets $a_{t}$, the mass of individuals searching for high- or low-wage jobs, and search intensity for workers in firm $L$ to maximize $\mathbb{E}_{0} \sum_{t=0}^{\infty} \beta^{t} \mathbf{u}\left(c_{h, t}\right)$, where $\mathbf{u}^{\prime}>0, \mathbf{u}^{\prime \prime}<0$, and $\beta \in(0,1)$, subject to its perceived laws of motion for employment in each sector and the constraint

$$
c_{h, t}+\kappa\left(s_{t}\right) n_{L, t}+a_{t}=R_{t-1} a_{t-1}+w_{H, t} n_{H, t}+w_{L, t} n_{L, t}+\chi\left(u_{H, t}+u_{L, t}\right)+\Pi_{y, t}+T_{t},
$$

where: $\kappa(s)$ is the resource cost of on-the-job search $\left(\kappa^{\prime}>0\right.$ and $\left.\kappa^{\prime} \geq 0\right) ; R$ is the gross real interest rate; $w_{H}\left(w_{L}\right)$ is the real wage in firm $H(L) ; \chi$ is the flow value of unemployment; $\Pi_{y}$ are profits from the final goods firm; and $T$ are lump-sum taxes. ${ }^{6}$ Let $\mathbf{W}_{j, t}$ be the household's value of employment in firm-type $j \in\{H, L\}$. The first-order conditions yield a standard consumption-savings are

${ }^{6}$ Per the earlier development and equations (1) and (2) the household's perceived laws of motion for employment

$$
n_{H, t+1}=(1-\rho)\left[n_{H, t}+f_{H, t}\left(u_{H, t}+s_{t} n_{L, t}\right)\right],
$$

CInternational Monetary Fund. Not for Redistribution 
Euler equation

$$
\mathbf{u}^{\prime}\left(c_{h, t}\right)=\beta R_{t} \mathbb{E}_{t} \mathbf{u}^{\prime}\left(c_{h, t+1}\right)
$$

and an optimal search intensity condition

$$
\kappa^{\prime}\left(s_{t}\right)=(1-\rho) f_{H, t} \mathbb{E}_{t} \Xi_{t+1 \mid t}\left[\mathbf{W}_{H, t+1}-\mathbf{W}_{L, t+1}\right]
$$

where: $\Xi_{t+1 \mid t} \equiv \beta \mathbf{u}^{\prime}\left(c_{h, t+1}\right) / \mathbf{u}^{\prime}\left(c_{h, t}\right)$. This last condition equates the marginal cost of a worker in firm $L$ searching for a job in firm $H$, which is given by $\kappa^{\prime}\left(s_{t}\right)$, to the expected net marginal benefit of a job-to-job transition, which is given by the net capital gain between the two types of jobs. The household allocates unemployed search activity across sectors until the value of such activity is equalized (Krause and Lubik, 2006, 2010; this result is akin to a no arbitrage condition holding as far as search activity goes). ${ }^{7}$

\section{B. Production}

The final goods firm purchases output from firms $H$ and $L$ to produce final output via the constantreturns-to-scale function $y_{t}=z_{t} y\left(y_{H, t}, y_{L, t}\right)$, where: $z$ is total factor productivity (TFP); and $y_{j}$ is intermediate output produced by type $j \in\{H, L\}$ firms. The final goods firm chooses inputs to maximize $\Pi_{y, t}=\left[z_{t} y\left(y_{H, t}, y_{L, t}\right)-p_{H, t} y_{H, t}-p_{L, t} y_{L, t}\right]$, where $p_{j}$ are prices relative to the price of final output (which is normalized to 1$){ }^{8}$

Intermediate firm $j \in\{H, L\}$ is owned by entrepreneur $j$, who chooses consumption $c_{j, t}$, vacancies $v_{j, t}$, desired employment $n_{j, t+1}$, next period's capital stock $k_{j, t+1}$, and borrowed funds $l_{j, t}$, to $\operatorname{maximize} \mathbb{E}_{0} \sum_{t=0}^{\infty} \beta_{j}^{t} \mathbf{u}\left(c_{j, t}\right)$, where $\mathbf{u}^{\prime}>0, \mathbf{u}^{\prime \prime}<0$, and $0<\beta_{j}<\beta$. This difference in subjective discount factors between entrepreneurs and the household is standard in the literature on fi-

and

$$
n_{L, t+1}=(1-\rho)\left[n_{L, t}+f_{L, t} u_{L, t}-f_{H, t} s_{t} n_{L, t}\right]
$$

\footnotetext{
${ }^{7}$ Optimal search activity implies that $\mathbf{U}_{L, t}=\mathbf{U}_{H, t}=\mathbf{U}_{t}$. See the Appendix for detailed derivations and technical statements of employment and unemployment values.

${ }^{8}$ The first-order conditions associated with this problem implicitly define $p_{H, t}$ and $p_{L, t}$ such that:
}

$$
p_{H, t}=z_{t} y_{y_{H}}\left(y_{H, t}, y_{L, t}\right) \text { and } p_{L, t}=z_{t} y_{y_{L}}\left(y_{H, t}, y_{L, t}\right) \text {. }
$$


nancial frictions and guarantees that the firm's collateral constraint is binding in the neighborhood of the steady state—see, for example, Iacoviello (2015). Importantly, per related literature (Jermann and Quadrini, 2012), the presence of binding constraints is what allows usage of the collateral constraints implied by the model to construct time series for financial shocks using data on firms' liabilities, capital stock, and wage bill (see the Appendix for further details). This problem is subject to

$$
\begin{gathered}
c_{j, t}=p_{j, t} y_{j, t}-w_{j, t} n_{j, t}-\gamma_{j} v_{j, t}-i_{j, t}+l_{j, t}-R_{t-1} l_{j, t-1}, \\
k_{j, t+1}=(1-\delta) k_{j, t}+i_{j, t},
\end{gathered}
$$

which is a standard equation of motion for capital with $\delta$ denoting the depreciation rate and $i_{j}$ investment, and ${ }^{9}$

$$
R_{t} l_{j, t} \leq \eta_{t} k_{j, t+1}-\eta_{w} w_{j, t} n_{j, t}
$$

In the first constraint: $y_{j}$ is equal to the constant returns to scale production function $F\left(n_{j}, k_{j}\right) ; w_{j} n_{j}$ is the wage bill; and $\gamma_{j} v_{j}$, is the vacancy bill, where $\gamma_{j}$ is a standard exogenous flow cost; in addition, firm $j$ borrows $l_{j, t}$ and must repay $R_{t-1} l_{j, t-1}$ for the previous period's borrowed funds, where $R_{t-1}$ is the gross real interest rate on these funds. ${ }^{10}$ Finally, the collateral constraint shows that the value of firm $j$ 's liabilities $R l_{j}$ cannot exceed a fraction $\eta$ of the value of firm $j$ 's capital net of the firm's wage bill $w_{j} n_{j}$, where $\eta$ denotes the firm's time-varying borrowing capacity, which has mean $\bar{\eta}$ and is subject to exogenous fluctuations that we interpret as financial shocks; the borrowing capacity parameter is common to both firms. For simplicity, we initially assume that firms need to finance the whole wage bill with borrowed funds, which is a standard assumption in related literature (we explore the relevance of this assumption as part of our robustness checks). Thus, $\eta_{w}=1$. In addition, the firm's maximization problem is subject to each firm's sector-specific perceived law of motion for employment. ${ }^{11}$

\footnotetext{
${ }^{9}$ We introduce standard convex capital adjustment costs for both firms when we take the model to the data. For expositional simplicity, we abstract from these costs when presenting the model.

${ }^{10}$ Gilchrist and Zakrajšek (2012) document the link between business cycle fluctuations and credit spreads in the U.S., showing that the latter increased dramatically during the GFC. We abstract from introducing explicit lendingdeposit spreads in our benchmark specification for expositional purposes, so that the real interest rate on borrowed funds is the same as the real interest rate on assets owned by the household.
}

${ }^{11}$ Per the earlier development and equations (1) and (2) the firms's sector-specific perceived laws of motion for employment are

$$
n_{H, t+1}=(1-\rho)\left(n_{H, t}+v_{H, t} q_{H, t}\right)
$$

and

$$
n_{L, t+1}=(1-\rho)\left(n_{L, t}+v_{L, t} q_{L, t}-f_{H, t} s_{t} n_{L, t}\right)
$$


The timing of decisions is as follows. At the beginning of period $t$, TFP and financial shocks materialize and then entrepreneur $j \in\{H, L\}$ makes decisions over choice variables. Per the collateral constraint that firms face, entrepreneurs can partially offset an exogenous deterioration in borrowing capacity $\eta$ by increasing $k_{j, t+1}$ or reducing $l_{j, t}$, or both (concavity of the production function implies that in fact entrepreneurs will change both). The fact that entrepreneurs can optimally change their assets and liabilities in response to financial shocks is consistent with standard models of financial frictions (Jermann and Quadrini, 2012; Iacoviello, 2015). In turn, for a given gross real interest rate, entrepreneurs' optimal choice over assets and liabilities, coupled with the change in borrowing capacity, determines equilibrium financial conditions.

The first-order conditions yield a capital Euler equation that takes into account the value of capital as collateral. For $j \in\{H, L\}$,

$$
\left[1-\lambda_{j, t} \eta_{t}\right]=\mathbb{E}_{t} \Xi_{t+1 \mid t}^{j}\left\{p_{j, t+1} F_{k_{j}}\left(n_{j, t+1}, k_{j, t+1}\right)+(1-\delta)\right\}
$$

where $\Xi_{t+1 \mid t}^{j} \equiv \beta \mathbf{u}^{\prime}\left(c_{j, t+1}\right) / \mathbf{u}^{\prime}\left(c_{j, t}\right)$, and an optimal choice over borrowed funds

$$
1-R_{t} \lambda_{j, t}=\mathbb{E}_{t} \Xi_{t+1 \mid t}^{j} R_{t}
$$

where $\lambda_{j}$ is firm $j$ 's multiplier on its collateral constraint (normalized by the marginal utility of consumption). In addition, firm $H$ has the following job creation condition:

$$
\frac{\gamma_{H}}{q_{H, t}}=(1-\rho) \mathbb{E}_{t} \Xi_{t+1 \mid t}^{H}\left\{p_{H, t+1} F_{n_{H}}\left(n_{H, t+1}, k_{H, t+1}\right)-w_{H, t+1}\left[1+\eta_{w} \lambda_{H, t+1}\right]+\frac{\gamma_{H}}{q_{H, t+1}}\right\}
$$

which incorporates the presence of the wage bill in firms' collateral constraints, while firm $L$ has the job creation condition

$$
\frac{\gamma_{L}}{q_{L, t}}=(1-\rho) \mathbb{E}_{t} \Xi_{t+1 \mid t}^{L}\left\{\begin{array}{c}
p_{L, t+1} F_{n_{L}}\left(n_{L, t+1}, k_{L, t+1}\right)-w_{L, t+1}\left[1+\eta_{w} \lambda_{L, t+1}\right] \\
+\left(1-s_{t+1} f_{H, t+1}\right) \frac{\gamma_{L}}{q_{L, t+1}}
\end{array}\right\}
$$

which includes the effective probability that workers in firm $L$ transition to employment in firm $H$ in the future, $s_{t+1} f_{H, t+1}$. 
The capital Euler equation is standard, except for the presence of the collateral constraint multiplier. All else equal, a tighter collateral constraint (reflected in a higher $\lambda_{j}$ ) reduces the marginal cost of accumulating capital. The demand for external borrowing equates the marginal benefit from borrowed funds to the expected marginal cost. All else equal, a tighter constraint (reflected in a higher $\lambda_{j}$ ) reduces the marginal benefit of borrowing funds (the left-hand-side of the Euler equation). Of note, to the extent that adverse financial shocks induce a rise in $\lambda_{j}$, this will reduce firms' discounting of the future value of capital and employment relationships, causing both future investment and hiring to contract in the aftermath of such shock. This is a key channel through which financial shocks affect future input decisions. In fact, a second channel works through the impact of movements in firms' credit tightness on firms' effective bargaining power over wage negotiations, which we describe below. (Quantitatively, this second channel is second order relative to the first channel.) Finally, the job creation condition for each firm equates the expected marginal cost of posting a vacancy to the expected marginal benefit of a vacancy, where the marginal benefit is affected by the need to borrow funds to finance the wage bill. In particular, a tightening of the collateral constraint (reflected in a higher $\lambda_{j}$ ), all else equal, reduces firms' expected marginal benefit from posting a vacancy. ${ }^{12}$

\section{Wage Determination}

Wages are determined via Nash bargaining with no commitment to the future path of wages, and we assume that once an on-the-job search accepts a type $H$ job s/he cannot go back to the type L job. In particular, denoting by $\phi$ the bargaining power of workers, the implicit Nash wage equations that determine the wage $w_{j, t}$ for $j \in\{H, L\}$ is

$$
\mathbf{W}_{j, t}-\mathbf{U}_{j, t}=\frac{\phi}{(1-\phi)\left[1+\lambda_{j, t}\right]} \mathbf{J}_{j, t}
$$

\footnotetext{
${ }^{12}$ A note regarding the collateral constraint specification we adopt in the model: an alternative way to write the constraint would be to include the price of capital such that firms' ability to borrow depends on the market value of capital. We abstract from including the price of capital in $\eta_{t} k_{j, t+1}$ since the construction of financial shocks, which follows closely the methodology outlined by Jermann and Quadrini (2012) and is described in more detail in the Appendix, requires that all the elements in the constraint be observable in the data. While we can easily find empirical counterparts for firms' liabilities, capital stock, and wage bills, we do not have aggregate data on the price of firms' capital. Given that our main experiment consists of using the shocks constructed using real time series, our specification follows Jermann and Quadrini (2012) and abstracts from incorporating the price of capital in the firms' collateral constraint.
} 
where $\mathbf{J}_{j, t}$ is the value to a firm of having an additional worker. This value is affected by the collateral constraint since firms need to finance their wage bill using borrowed funds, implying that the effective wage costs for each firm are affected by financial conditions (embodied partly in the collateral multiplier). Following related literature, there is free entry into vacancy posting so that the value of a vacancy is zero.

Given the presence of different discount factors between firms and the household as well as the timing convention for the evolution of employment we cannot obtain a closed-form solution for wages. ${ }^{13}$ However, per standard properties of firms' value functions, $\mathbf{J}_{j, t}$ implicitly embodies labor market tightness in sector $j$, which means that wages will be affected by financial conditions through two channels, as alluded to above. First, movements in the collateral multiplier as a result of financial distress will directly influence wage fluctuations when firms must use borrowed funds to cover their wage bill via changes in workers' effective bargaining power. Second and more importantly, changes in financial conditions affect firms' discounting of the future value of capital and employment relationships, with higher financial distress causing the future value of employment to contract sharply as firms put more weight, in relative terms, on present (as opposed to future) economic and financial conditions (we discuss this more formally below). Firms' recruiting decisions shape movements in market tightness (via changes in vacancies) and ultimately determine the extent of fluctuations in wages and employment. As such, financial shocks play a key role in amplifying changes in vacancy postings and, by extension, wages and therefore labor income as well.

\section{Closing the Model and Competitive Equilibrium}

Unemployment benefits are financed solely via lump-sum taxation such that the government's budget constraint is: $T_{t}=\chi\left(u_{H, t}+u_{L, t}\right)$. In turn, the economy's resource constraint is given by

$$
y_{t}=c_{t}+i_{H, t}+i_{L, t}+\kappa\left(s_{t}\right) n_{L, t}+\gamma_{H} v_{H, t}+\gamma_{L} v_{L, t},
$$

where: $c_{t} \equiv c_{h, t}+c_{H, t}+c_{L, t}$ denotes total private consumption; and the costs of posting vacancies and searching for employment are resource costs. In a competitive equilibrium, taking the stochastic processes $\left\{z_{t}, \eta_{t}\right\}$ as given, the state-contingent allocations and prices $\left\{n_{H, t}, n_{L, t}, R_{t}, s_{t}, c_{H, t}, i_{H, t}\right.$,

\footnotetext{
${ }^{13}$ In the absence of collateral constraints and with all subjective discount factors being equal to each other, the wage equations would be identical to those in Krause and Lubik (2006, 2010).
} 
$\left.l_{H, t}, \theta_{H, t}, k_{H, t}, \lambda_{H, t}, c_{L, t}, i_{L, t}, l_{L, t}, \theta_{L, t}, k_{L, t}, \lambda_{L, t}, w_{H, t}, w_{L, t}, u_{L, t}\right\}_{t=0}^{\infty}$ and $\left\{p_{H, t}, p_{L, t}, y_{t}, u_{H, t}, c_{h, t}\right\}_{t=0}^{\infty}$ satisfy: the laws of motion for employment in $L$ and $H$ firms; the household's consumption-savings Euler equation; the optimal level of OTJ search intensity; the $H$ firm's consumption, law of motion for capital, (binding) collateral constraint, job creation condition, capital Euler equation, and optimal demand for borrowed funds; the $L$ firm's consumption, law of motion for capital, (binding) collateral constraint, job creation condition, capital Euler equation, and optimal demand for borrowers funds; the implicit Nash wage equations for $H$ and $L$ employment; the arbitrage condition for individuals searching for employment in the two firm categories; the relative prices of intermediate firm output; the definition of total output; the definition of total unemployment; and the economy-wide resource constraint. A list of the model's equilibrium conditions is presented in the Appendix.

\section{BACKGROUND FOR SIMULATION ANALYSIS}

A period in the model is a quarter. The model's stochastic processes and calibration stem from focusing on data spanning 1956:Q1 through 2015:Q2. However, following Jermann and Quadrini (2012), the results we present focus on the period starting in 1985:Q1 to avoid contamination by non-modeled structural changes that took place in the early 1980s. ${ }^{14}$ (Our analysis goes throug 2015:Q2, only, as this is the last time period for which we are able to perform our paper's main analysis given limitations on the availability of data needed to construct TFP and financial shocks.)

\section{A. Stochastic Processes}

Following Jermann and Quadrini (2012), we construct the TFP series using data on total non-farm employment from the BLS, a constructed series for the capital stock using National Income and Product Accounts (NIPA) and Flow of Funds data, and a standard Cobb-Douglas production function with labor share equal to $0.66 .{ }^{15}$ The construction of the series for $\eta_{t}$ is less straightforward

\footnotetext{
${ }^{14}$ We discuss results spanning 1956:Q1 through 2015:Q2 in the Appendix. (The benchmark model performs quite well in capturing U.S. macro time series prior to 1985 as well.)

${ }^{15}$ In particular, we use the following series: capital expenditures (FA145050005.Q), consumption of capital by corporate businesses (FA106300053.Q), and consumption of capital by non-corporate businesses (FA116300081.Q) to construct the capital stock series. For output, we use real GDP from NIPA (Table 1.1.6). We use the Business Price Index to deflate all nominal variables. All relevant details are in the Appendix.
} 
compared to Jermann and Quadrini (2012) as our model features two firms. To facilitate the construction of the series for financial conditions, we assume that $\eta_{t}$ does not differ across firms (implying that both firms face the same aggregate financial process and the same level of financial conditions). ${ }^{16}$ We first combine the firms' collateral constraints to obtain an aggregate collateral constraint that we can take to the data:

$$
R_{t} l_{L, t}+R_{t} l_{H, t} \leq \eta_{t}\left(k_{L, t+1}+k_{H, t+1}\right)-\eta_{w}\left(w_{L, t} n_{L, t}-w_{H, t} n_{H, t}\right)
$$

Defining $l \equiv l_{H}+l_{L}, k \equiv k_{H}+k_{L}$, and $w n \equiv w_{H} n_{H}+w_{L} n_{L}$ as, respectively, total borrowed funds, the total capital stock, and the total wage bill, assuming that the constraint binds, and $\eta_{w}=1$, we can write the condition above more compactly as $R_{t} l_{t}=\eta_{t} k_{t+1}-w_{t} n_{t}$. Then, we have $\eta_{t}=$ $\left(R_{t} l_{t}+w_{t} n_{t}\right) / k_{t+1}$. Each of the elements on the right-hand-side in this last expression can be directly measured in the data. Specifically, we use real liabilities of nonfinancial corporate and noncorporate businesses for $R l$, the total capital stock for $k$, and real total compensation of employees (i.e., the total wage bill and also our proxy for total labor income) for wn. (A more detailed description of the construction of these series is presented in the Appendix.)

Jermann and Quadrini (2012) use a vector autoregression (VAR) specification to pin down the lag processes and disturbances associated with $z$ and $\eta$ and find that there are spillover effects between TFP and financial conditions (i.e., in this context the null hypothesis that one series does not Granger cause the other cannot be rejected). One objective of our analysis is to determine to what extent $f$ nancial shocks on their own contribute to better matching key macro time series amid job-to-job flows and independent TFP shocks. As such, abstracting from spillover effects between shocks provides a more transparent notion of the two structural shocks that may drive business cycles in our model and in the data.

In order to abstract from spillover effects between shocks, we purge TFP and financial shocks from their interaction effects by following the methodology in Fujita and Ramey (2007). We refer to this purging procedure as FR shock purging. As shown in the Appendix, our procedure implies a substantially better fit of the benchmark model compared to a model where we do not remove spillover effects between shocks.

\footnotetext{
${ }^{16}$ Assuming asymmetries in the level of $\eta$ across firm categories does not change our main conclusions since ultimately what matters is the magnitude of a shock (in spite of differences in steady-state borrowing capacity), and this magnitude does not change with asymmetries in borrowing capacity across firms.
} 
Specifically, the FR shock purging methodology is as follows. Let $a_{t} \neq b_{t}$ and $a_{t}, b_{t} \in\left\{\ln z_{t}, \ln \eta_{t}\right\}$, where $\ln z_{t}$ and $\ln \eta_{t}$ are the cyclical components of the log of $z_{t}$ and $\eta_{t}$ obtained using an HP filter with smoothing parameter equal to 1600 . To characterize the dynamic relationship between these variables, we run the following recursive VAR: $X(L)\left[\begin{array}{ll}a_{t} & b_{t}\end{array}\right]^{\prime}=\left[\begin{array}{ll}\epsilon_{t}^{a} & \epsilon_{t}^{b}\end{array}\right]^{\prime}$, where $X(L)$ is a lag polynomial, and $\epsilon_{t}^{a}$ and $\epsilon_{t}^{b}$ are the reduced-form residuals of the two equations (a host of information criteria tests suggest an optimal lag order of 2, which we use; other lag specifications yield nearly identical results). Granger causality tests fail to reject the null that each variable in the system does not Granger cause the other and do not suggest a clear-cut ordering for the recursive VAR since failure to accept the null occurs at the 1 percent level for each variable.

Given the lack of information on a clear-cut recursive ordering and no convincing economic argument for TFP shocks being more exogenous relative to financial shocks (and vice versa), we run the recursive VAR twice by first letting $a_{t}=\ln z_{t}$ and then letting $a_{t}=\ln \eta_{t}$. In other words, we first assume that $\ln z_{t}$ is the most exogenous variable, and we then assume that $\ln \eta_{t}$ is the most exogenous variable. In each case, $a$ is purged of feedback effects and its exogenous component, denoted by $\hat{a}$, can be determined from the structural shocks by operationalizing the process $\hat{X}_{11}(L) \hat{a}_{t}=$ $\hat{\epsilon}_{t}^{a}$, where: $\hat{X}_{11}(L)$ is the estimated value of the lag polynomial in the first row and first column of $X(L)$; and $\hat{\epsilon}_{t}^{a}$ is the structural shock that is estimated. Note that the feedback effects are removed by setting the lag polynomial $\hat{X}_{12}(L)$, which is associated with the variable $b$, equal to zero (an alternative approach would be to commit to an ordering and then obtain exogenous components of $a$ and $b$ by operationalizing the processes $\hat{X}_{11}(L) \hat{a}_{t}=\hat{\epsilon}_{t}^{a}$ and $\hat{X}_{22}(L) \hat{b}_{t}=\hat{\epsilon}_{t}^{b}$; regardless of the ordering, this alternative specification yields very similar results to those attained by by the methodology we implement).

With the exogenous components $\ln \hat{z}_{t}$ and $\ln \hat{\eta}_{t}$ in hand, we can estimate two independent shocks in the model. To do so, we model each series as an autoregressive (AR) process for which information criteria suggest an optimal lag order of 1 . As such, the estimated independent shocks in the model for TFP and $\eta$ are obtained using the following two specifications, respectively: $\ln \hat{z}_{t}=\rho_{z} \ln \hat{z}_{t-1}+$ $\varepsilon_{t}^{z}$, and $\ln \hat{\eta}_{t}=\rho_{\eta} \ln \hat{\eta}_{t-1}+\varepsilon_{t}^{\eta}$. This approach delivers the estimates $\hat{\rho}_{z}=0.717$ and $\hat{\rho}_{\eta}=0.720$, both of which are significant at the 1 percent level, and the standard deviation estimates for the residuals $\varepsilon^{z}$ and $\varepsilon^{\eta}$ are given, respectively, by $\hat{\sigma}_{z}=0.004$ and $\hat{\sigma}_{\eta}=0.011$.

Figure 2 shows the resulting time series for $\ln \hat{z}$ and $\ln \hat{\eta}$ as well as their respective shocks, $\varepsilon_{t}^{z}$ and $\varepsilon_{t}^{\eta}$. 
As the figures suggest, the series for $\ln \hat{z}$ and $\ln \hat{\eta}$ are fairly positively correlated (the contemporaneous cyclical correlation is 0.392 ).

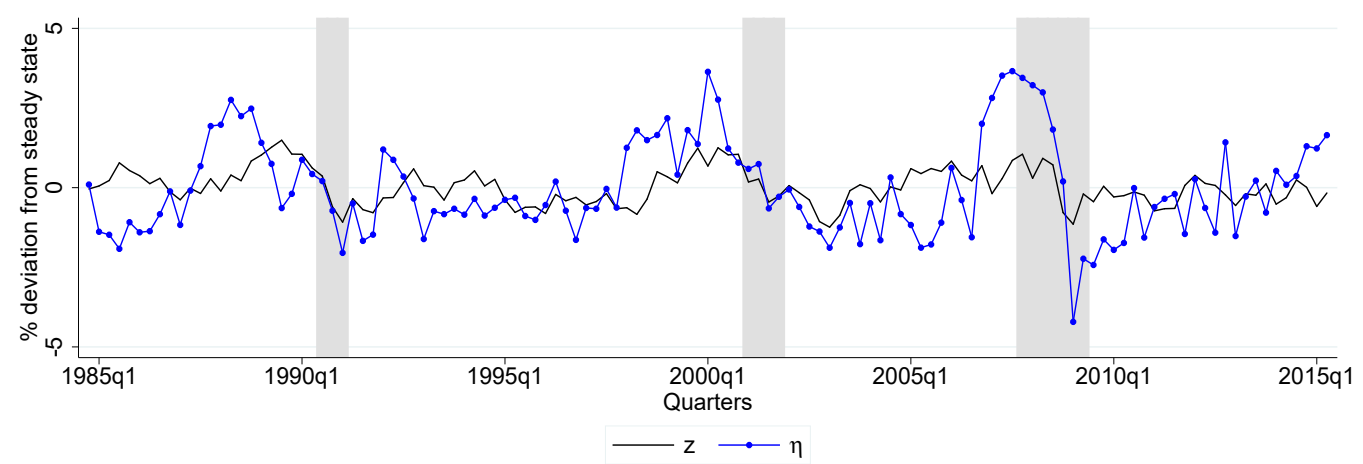

(a) Cyclical Dynamics of TFP

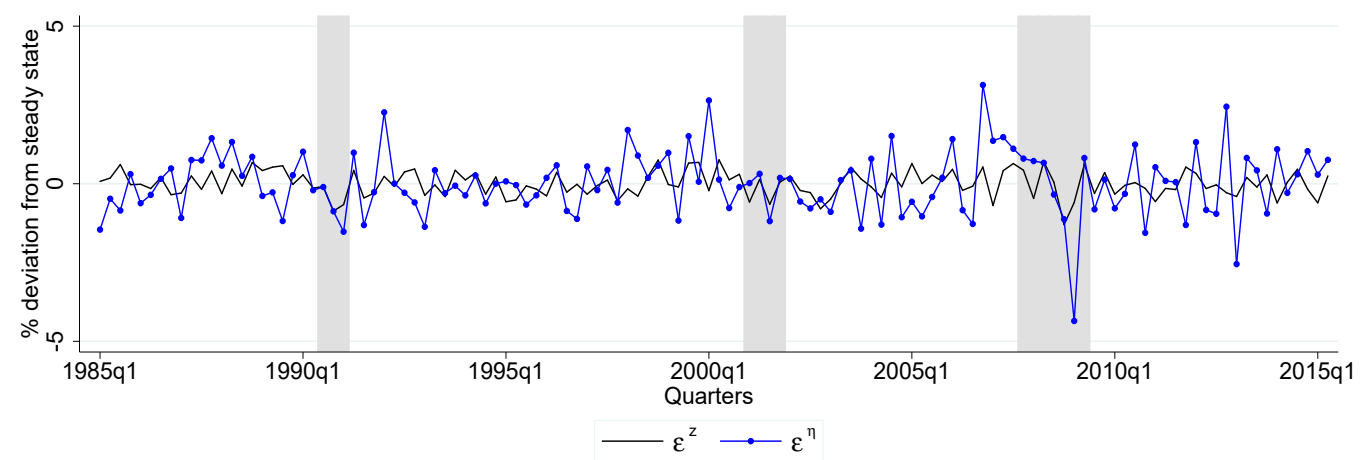

(b) TFP Shocks

Figure 2: TFP Shocks

Top panel: cyclical dynamics of TFP $(z)$ and financial conditions $(\eta)$. Bottom panel: TFP shocks $\left(\varepsilon^{z}\right)$ and financial shocks $\left(\varepsilon^{\eta}\right)$. Data span: 1985:Q1-2015:Q2. Recession quarters are marked in gray. The cyclical components of the data are based off the log deviations of the data from trend using an HP filter with smoothing parameter equal to 1600 .

\section{B. Functional Forms and Parameter Selection}

All utility functions are CRRA: $\mathbf{u}\left(c_{j}\right)=c_{j}^{1-\sigma} /(1-\sigma)$ for $j=h, H, L$ where $\sigma$ is the CRRA parameter. The production functions of firms $H$ and $L$ are Cobb-Douglas: $y_{j, t}=\left(n_{j, t}\right)^{1-\alpha_{j}}\left(k_{j, t}\right)^{\alpha_{j}}$ where $0<\alpha_{j}<1$ for $j=H, L$. The final goods production function is also Cobb-Douglas such that

$$
y_{t}=z_{t} \underbrace{\left(\left(n_{H, t}\right)^{1-\alpha_{H}}\left(k_{H, t}\right)^{\alpha_{H}}\right)^{1-\alpha}}_{=y_{H, t}} \underbrace{\left(\left(n_{L, t}\right)^{1-\alpha_{L}}\left(k_{L, t}\right)^{\alpha_{L}}\right)^{\alpha}}_{=y_{L, t}} \text {, }
$$


where: $\alpha \in(0,1)$. We introduce capital adjustment costs using the cost function $\Phi\left(k_{j, t+1} / k_{j, t}\right)=$ $\left(\varphi_{k} / 2\right)\left(k_{j, t+1} / k_{j, t}-\delta\right)^{2} k_{j, t}$ for $j=H, L$ where $\varphi_{k}>0$. The matching functions are Cobb-Douglas: $m=M(\cdot)^{\mu}(\cdot)^{1-\mu}$, where $M$ is the common matching efficiency parameter, and $\mu$ is the common matching elasticity parameter. The cost function for OTJ search is $k\left(s_{t}\right)=\kappa\left(s_{t}\right)^{\eta_{s}}$, with $\kappa>0$ and $\eta_{s} \geq 1$

The household's discount factor $\beta$ is 0.99 . In turn, the firms' discount factors $\beta_{H}$ and $\beta_{L}$ are set to 0.97. ${ }^{17}$ The firms' discount factors imply an interest spread of roughly 2 percent, which is consistent with the average empirical spread between the weighted-average effective loan rate for commercial and industry loans (obtained from the Survey of Terms of Business Lending) and the federal funds rate. The value for the CRRA parameter $\sigma$ is 1, consistent with the U.S. business cycle literature. Furthermore, we set $\alpha_{H}=\alpha_{L}=0.34$ and $\alpha=0.4$, which jointly imply an aggregate labor share of 0.66 consistent with standard macro values and our estimation of the TFP process. ${ }^{18}$ The job separation rate $\rho$ is 0.10 , which is consistent with other studies (see, for example, Arseneau and Chugh, 2012). The matching elasticity and bargaining power parameters, $\mu$ and $\phi$, are set to 0.4 and 0.5 , respectively (Petrongolo and Pissarides, 2001; Shimer, 2005). The curvature parameter of the onthe-job search cost function $\eta_{s}$ is set to 1 (Merz, 1995), and the depreciation rate of capital is set to 0.025 , which is consistent with U.S. empirical estimates. ${ }^{19}$

The parameters $\chi, \kappa, M, \bar{\eta}, \varphi_{k}, \gamma_{L}$ and $\gamma_{H}$, are chosen so that the model matches the following moments in the data: a contemporaneous value of unemployment of roughly 60 percent of average wages (which lies close to Shimer, 2005, and is lower than in Hagedorn and Manovskii, 2008, and Hall and Milgrom, 2008; Hall and Milgrom suggest that the value of $\chi$ should not only capture the replacement rate but also home production and the value of leisure); a transition rate from low-wage jobs to high-wage jobs, $s f_{H} n_{L} /\left(n_{H}+n_{L}\right)$, equal to 0.05 ; a quarterly job-finding probability of

\footnotetext{
${ }^{17}$ Recall that, following the literature on financial frictions, we assume that intermediate firms face a lower discount factor than households to guarantee that the collateral constraint for each firm type binds in a neighborhood of the steady state (see Iacoviello, 2015, and others for a similar assumption).

${ }^{18}$ Krause and Lubik $(2006,2010)$ also assume a value of $\alpha=0.4$.

${ }^{19}$ In our reference OTJ search model (Krause and Lubik, 2006, 2010), convex OTJ search costs are needed to avoid indeterminacy. The reason we do not need to impose convex search costs in our model has to do with the difference in stochastic discount factors between firms and households (and not necessarily with the collateral constraints themselves). Effectively, the presence of the household's stochastic discount factor in the optimal OTJ search condition introduces enough concavity to guarantee a determinate equilibrium with linear OTJ search costs. This concavity vanishes when households own firms since, in such a case, optimal OTJ search ultimately only depends on firms' differential marginal cost of searching for workers.
} 
average unemployed individuals of roughly 0.80; total recruiting costs of 5 percent of total output (slightly higher than Arseneau and Chugh, 2012); a ratio of debt to (quarterly) GDP of 3.16, which is roughly consistent with the debt-to-GDP ratio of non-financial corporate and noncorporate firms for our sample period; the ratio of the volatility of investment to the volatility of output over the period 1985:Q1 through 2015:Q2, which is 4.25; and per-vacancy recruiting costs for low-wage firms that are one fourth of recruiting costs for high-wage firms (Krause and Lubik, 2006, 2010). ${ }^{20}$

As noted earlier, all else equal the more capital a firm has the greater its labor productivity, and following Pissarides (2000, Chapter 1), a higher labor productivity is associated with a greater opportunity cost of having an open position. In a reduced form way, this intuition is captured by assuming differential vacancy-posting costs, which in turn deliver wage and capital usage differentials between intermediate producers, with type- $H$ firms paying higher wages and using more capital than type- $L$ firms (see Acemoglu, 2001, as well). ${ }^{21}$ All told, the resulting calibration implies the following parameter values: $\chi=0.3527, \kappa=0.1118, M=0.6457, \gamma_{L}=0.1031, \gamma_{H}=0.4123$, $\bar{\eta}=0.5056, \varphi_{k}=0.806$. The value of $\kappa$ implies that $s f_{H}\left(1-u_{H}-u_{L}\right) /\left(f_{H} u_{H}+f_{L} u_{L}\right)$ is broadly in line with empirical estimates (Nagypál, 2005). Also, the value for the quarterly job-finding probability is in line with the average empirical value obtained following the methodology in Elsby, Michaels, and Solon (2009) and Shimer (2012) using post-war unemployment data. (The Appendix presents results for alternative parameterizations and versions of the benchmark model. From a comprehensive perspective and considering summary statistics for each alternative, our main conclusions regarding the relevance of OTJ search and financial shocks remain unchanged.)

\footnotetext{
${ }^{20}$ Reducing the differential in costs does not change our main conclusions regarding the relevance of the interaction between OTJ search and changes in financial conditions. Of further note, to calibrate the capital adjustment cost we log-linearize the model equations around their non-stochastic steady state and use a first-order approximation to the equilibrium conditions to obtain model-simulated data for 2100 periods. We drop the first 100 periods, apply an HP filter with smoothing parameter 1600 , and set $\varphi_{k}$ to match the relative volatility of investment in the data. As detailed below, though, in assessing the model's fit we generate simulated data by feeding in the empirical TFP and financial shocks as derived per the the earlier discussion. (Our main conclusions remain unchanged if instead we calibrate the capital adjustment cost based on model simulations that rely on the shock series we constructed using empirical time series. Importantly, this result implies that the main conclusions regarding our model's success in matching key facts in the data are not sensitive to the specific value of capital adjustment costs.)

${ }^{21}$ Our benchmark calibration delivers a wage differential of roughly 6 percent between $H$ and $L$ firms. Assuming other wage differentials does not affect our main conclusions regarding the interaction of OTJ search and financial conditions.
} 


\section{Results}

We henceforth refer to the model developed thus far as the Benchmark model. In this section we present our main results and argue that they indicate that the Benchmark model provides a particularly good fit to the empirical data. In the following section, we discuss the driving forces behind the Benchmark model's ability to match the empirical data. The model is operationalized by loglinearizing its equations around their non-stochastic steady state and using a first-order approximation to the equilibrium conditions to obtain model-simulated data. This simulated data results from feeding in the empirical TFP and financial shocks as derived per the discussion in the previous section. In all cases, we focus on business cycle data, which is obtained by applying an HP filter with smoothing parameter equal to 1600 to the natural logarithm of the level data. Also, recall that following Jermann and Quadrini (2012) the results we present focus on the period starting in 1985:Q1 to avoid contamination by non-modeled structural changes that took place in the early 1980s.

\section{A. Contour Analysis}

Because our main focus is to show assess the extent to which both OTJ search and financial shocks are important in accounting for the empirical data, our first set of results involves graphical comparison of empirical and model-generated time series for the major labor market and macro variables in our framework (output, consumption, i.e., the sum of consumption across economic agents, investment, i.e., the sum of investment across firms, unemployment, the ratio of aggregate vacancies, i.e., the sum of sectoral vacancies, to aggregate unemployment $v / u$, labor income, i.e., the sum of earnings across job types, and net quits) for three model specifications: the Benchmark model, a version of the Benchmark model in which OTJ search is shut down (No OTJS), and a version of the Benchmark model that abstracts from financial shocks (No Fin. Shocks). This analysis allows us to gauge how well each model is able to replicate the contour of the data. (Details pertaining to the noted two alternatives model specifications are presented in the Appendix.)

Figure 3 presents results for output: All three versions of the model track the empirical series quite well. Of note, the Benchmark model predicts a sharper contraction in output amid the GFC that is

more in line with the data relative to alternatives. All models predict a faster recovery of output following the GFC compared to the data. This feature is unsurprising, though, as all models omit in- 
come effects stemming from the steep decline in asset prices, including housing, that characterized the GFC as well as uncertainty and the slow process of balance-sheet repairs.

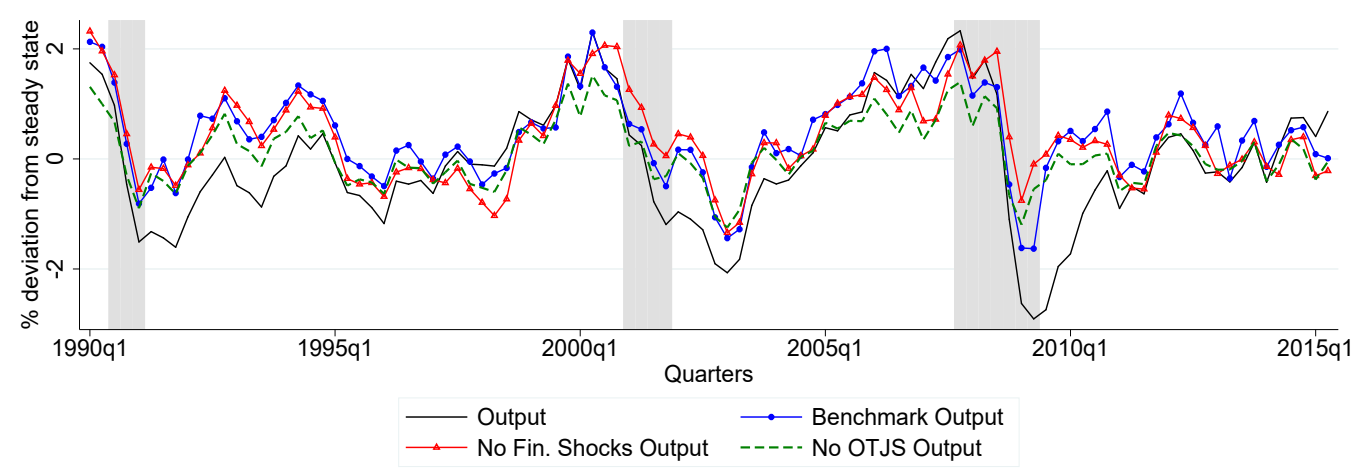

Figure 3: Cyclical Dynamics of Output

Cyclical dynamics (1985:Q1-2015:Q2) of output obtained using the natural logarithm of the data and an HP filter with smoothing parameter equal to 1600 . Recession quarters are marked in gray.

Figure 4 presents results for consumption: the Benchmark and No OTJS models track the empirical series quite well, but the No Fin. Shocks model predicts counterfactually flat consumption. As explained in detail later in the paper, this failure of the No Fin. Shocks model traces back to the impact of financial shocks on firms' collateral constraints, absent which a counterfactually smooth path for labor income (and therefore consumption) obtains.

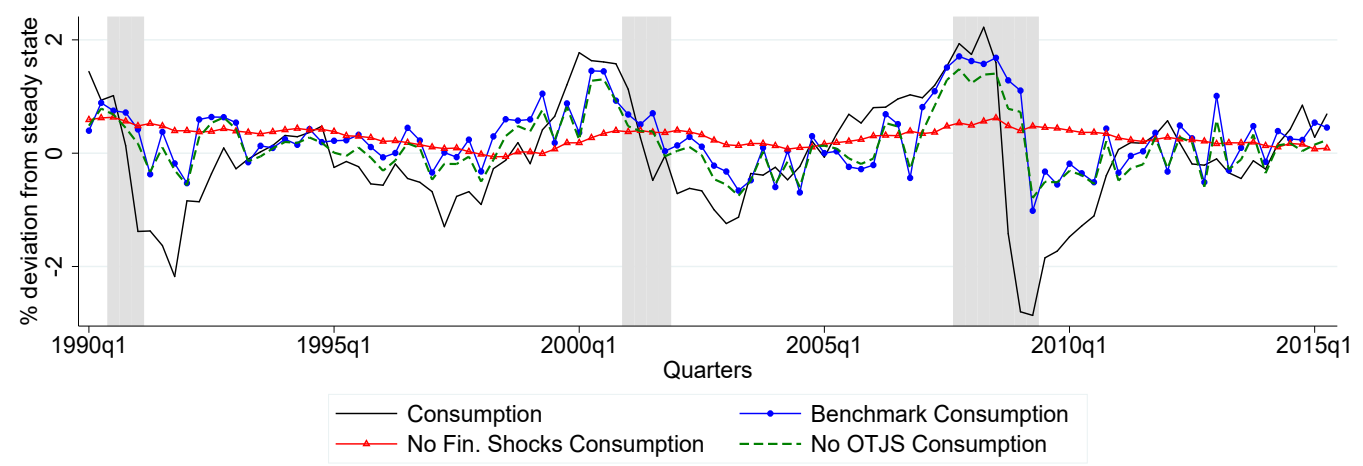

Figure 4: Cyclical Dynamics of Consumption

Cyclical dynamics (1985:Q1-2015:Q2) of consumption obtained using the natural logarithm of the data and an HP filter with smoothing parameter equal to 1600 . Recession quarters are marked in gray.

Figure 5 presents results for investment: All three versions of the model track the empirical series quite well, albeit with greater volatility. For reasons noted above, all models predict a faster recov- 
ery from the GFC, but relative to other alternatives, the Benchmark model once again exceeds in matching the extent of the contraction in investment amid the GFC.

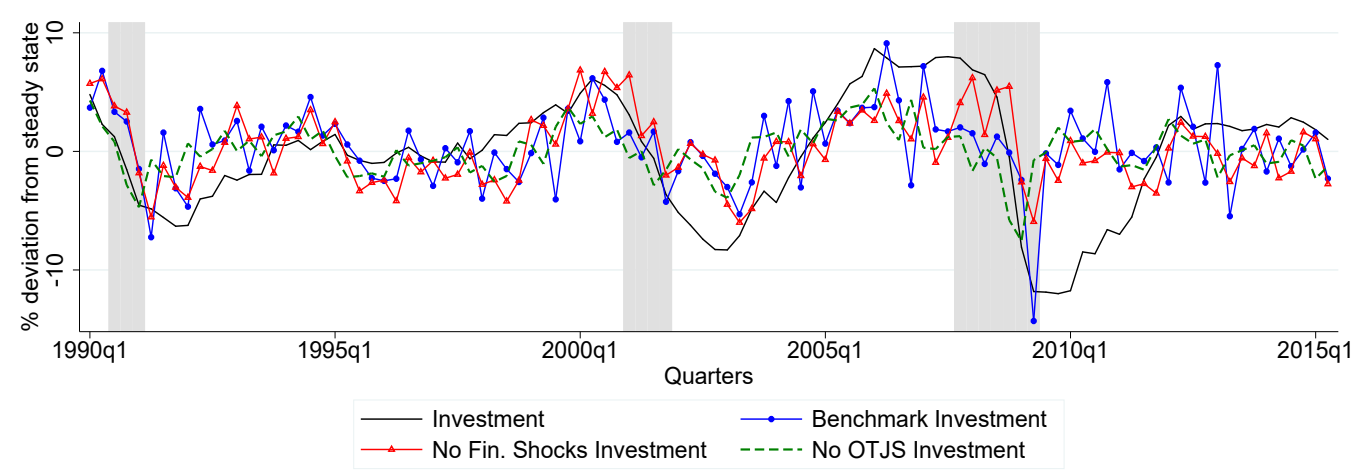

Figure 5: Cyclical Dynamics of Investment

Cyclical dynamics (1985:Q1-2015:Q2) of investment obtained using the natural logarithm of the data and an HP filter with smoothing parameter equal to 1600 . Recession quarters are marked in gray.

Figure 6 presents results for unemployment: The No OTJS model predicts counterfactually flat unemployment, while the Benchmark and No Fin. Shocks models do a better job of tracking the empirical series. The unemployment peaks of recession prior to the GFC are not matched particularly well, but this is not entirely surprising since the 1990 recession was intricately tied to oil price shockswhich our paper abstracts from-and both this recession and the 2001 recession were characterized by jobless recoveries, which also lie outside the scope of our analysis. Our paper does focus on the role of financial shocks, though, so it is noteworthy that the Benchmark model fares exceedingly well in approximating the unemployment peak amid the GFC (something that a model with OTJ search but without financial shocks cannot do); as was the case with earlier variables, though, the Benchmark model predicts a faster recovery from the GFC. As explained later in the paper, the flatness of unemployment under the No OTJS model is directly tied to OTJ search's impact as an amplification mechanism for aggregate labor-market dynamics. Having said that, even with OTJ search, financial shocks play a critical role in generating quantitatively factual changes in unemployment.

Figure 7 presents results for aggregate labor market tightness, i.e., the ratio of aggregate vacancies to aggregate unemployment, $v / u$ : Both the Benchmark and No Fin. Shocks models track the empirical data quite well, but the No OTJS model predicts a counterfactually flat v/u ratio. It is noteworthy that the Benchmark model fares exceedingly well among model alternatives in matching the contraction of the $v / u$ ratio amid the GFC. Again, though, all models predict a much faster recovery 


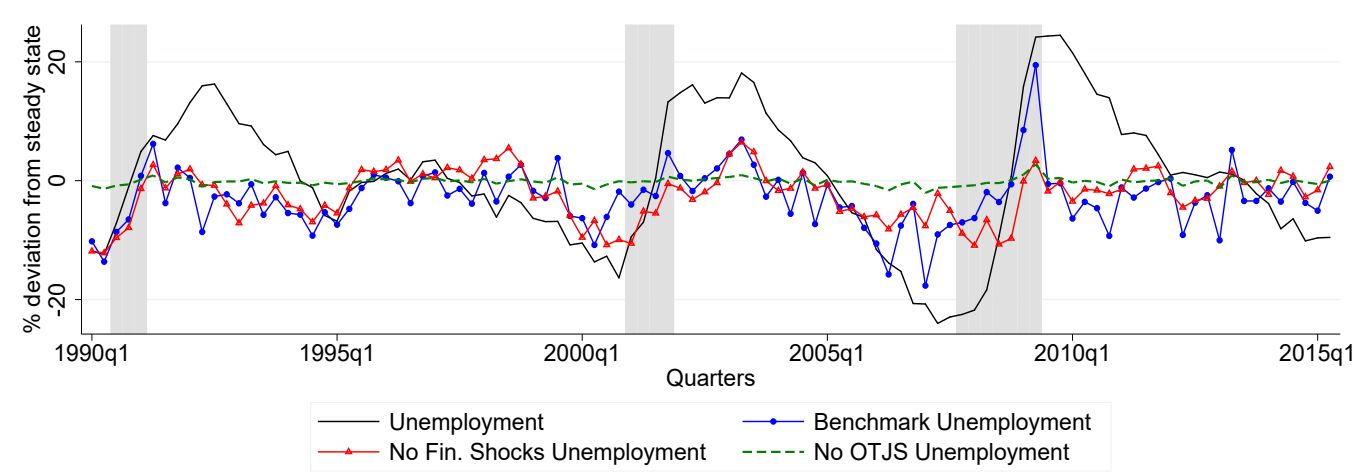

Figure 6: Cyclical Dynamics of Unemployment

Cyclical dynamics (1985:Q1-2015:Q2) of unemployment obtained using the natural logarithm of the data and an HP filter with smoothing parameter equal to 1600 . Recession quarters are marked in gray.

for reasons noted above. Also for similar reasons as noted earlier: it is unsurprising that no model matches exceedingly well the contraction of the $v / u$ ratio in recessions prior to the GFC; the flatness of the $v / u$ ratio under the No OTJS model is directly tied to OTJ search's impact as an amplification mechanism. Similar to the case of unemployment, even with OTJ search, financial shocks are central to producing a sharp contraction in market tightness amid the GFC.

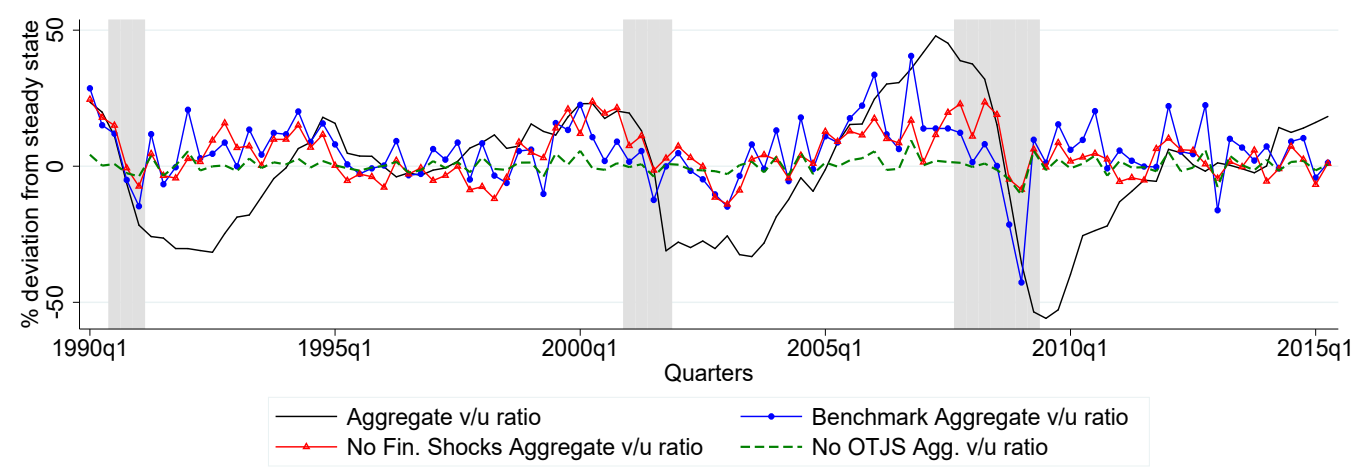

Figure 7: Cyclical Dynamics of the $v / u$

Cyclical dynamics (1985:Q1-2015:Q2) ofcthe $v / u$ ratio obtained using the natural logarithm of the data and an HP filter with smoothing parameter equal to 1600 . Recession quarters are marked in gray.

Figure 8 presents results for labor income: The No Fin. Shocks model predicts counterfactually flat labor income, but both the Benchmark and No OTJS models track the empirical series quite well. Note, though, that the Benchmark model fares best in matching the contraction of labor income amid the GFC, which, as explained later, stems from the combination of OTJ search as an amplification mechanism and the impact of financial shocks on wages and, therefore, labor income. Figure 
8 clearly highlights the role of financial shocks for better matching labor income and consumption dynamics.

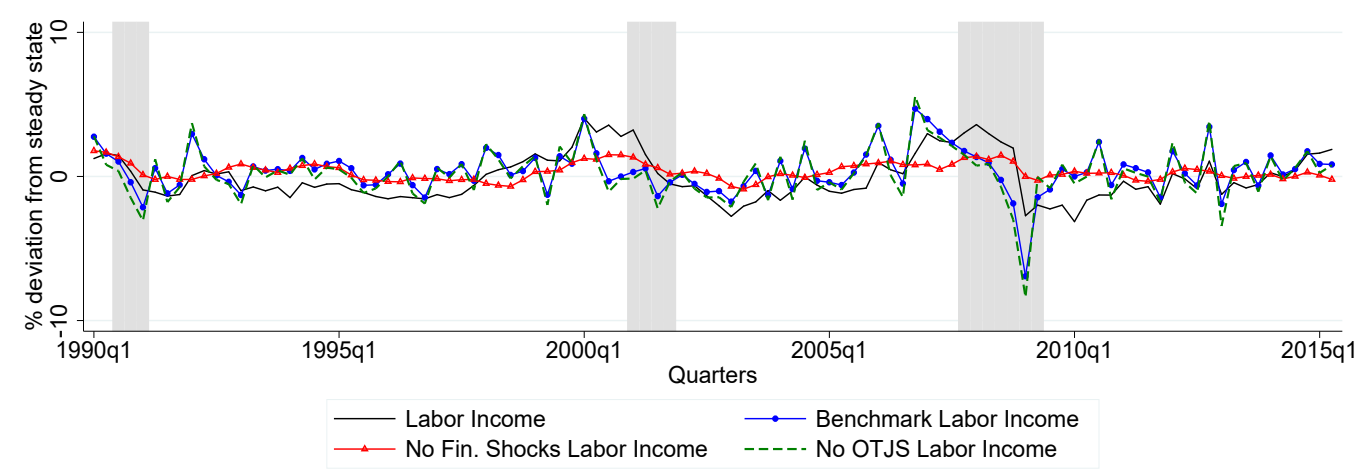

Figure 8: Cyclical Dynamics of Labor

Cyclical dynamics (1985:Q1-2015:Q2) of labor income obtained using the natural logarithm of the data and an HP filter with smoothing parameter equal to 1600 . Recession quarters are marked in gray.

Figure 9 presents results for the net quit rate (recall that we have two empirical reference for this series, one from Davis and Haltiwanger, 2014, and the other from JOLTS, whose construction is detailed in the paper's Introduction): The No OTJS model predicts zero quits by construction. The remaining alternative models' predictions involve greater volatility than the actual series, but the Benchmark model is the only one that matches the steep contraction in net quits amid the GFC. As explained in detail further below, the ability of the Benchmark model to capture the contraction of quits is a combination of its accounting for both OTJ search and financial shocks. Given the exceedingly good fit of net quits in the Benchmark model with the data and our emphasis on job-to-job flows, this result is particularly noteworthy.

In summary, our contour analysis suggests that the Benchmark model performs best in matching the behavior of all key labor market and macro aggregates compared to the No Fin. Shocks model and the No OTJS model. In particular, note that the No Fin. Shocks model predicts counterfactually flat consumption and labor income, while the No OTJS model predicts counterfactually flat unemployment and $v / u$. In contrast, the Benchmark model can jointly reconcile the behavior of consumption, labor income, unemployment and market tightness in the data. We conclude that our contour analysis supports our thesis that the interaction of financial shocks and OTJ search is important for matching the empirical behavior of a comprehensive set of labor market and macro aggregates in the data. 


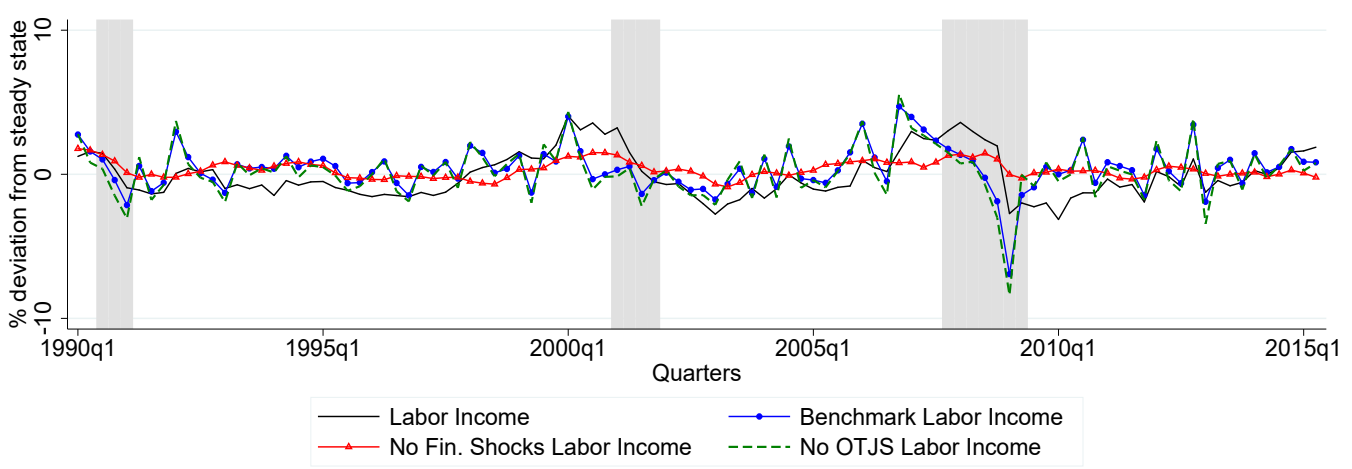

Figure 9: Cyclical Dynamics of Net Quits

Cyclical dynamics (1985:Q1-2015:Q2) of net quits obtained using the natural logarithm of the data and an HP filter with smoothing parameter equal to 1600. Net quits DH are constructed using data from Davis and Haltiwanger (2014) and data from the Current Population Survey; these data span 1990:Q2-2013:Q3. Net quits JOLTS are constructed using data from the Bureau of Labor Statistics' Job Openings and Labor Turnover Survey and the Current Population Survey; these data span 2001:Q1-2015:Q2. Recession quarters are marked in gray.

\section{B. Statistical Analysis}

We now complement the previous analysis by presenting key statistics pertaining to the Benchmark model and its No Fin. Shocks and No OTJS alternatives. These statistics are constructed based on the simulated time series for each model, which are obtained after feeding the constructed (TFP and financial) shocks into each model. The relevant statistics are presented in Table 1. Panel A of this table shows the relative standard deviation of key model variables relative to output for each model under comparison as well as the data. The Benchmark model performs quite well on all fronts in matching the data. In turn, we highlight the No OTJS model's exceedingly low relative volatilities of unemployment and the $v / u$ ratio compared to the data (which are well known features of this modeling framework); however, this model does deliver a relative consumption volatility that is in line with the data, and high labor-income volatility, albeit somewhat higher than in the data (these much are lesser known features of this modeling framework). In turn, the No Fin. Shocks model delivers relative volatilities of unemployment and the $v / u$ ratio that are much closer to the data compared to the No OTJS case (which are well known features of this modeling framework, i.e., the a context of OTJ search and TFP shocks, only); however, compared to the data this model yields exceedingly low relative volatilities of both consumption and labor income (these are much lesser known features of this modeling framework). 
Table 1: Statistics: 1985:Q1-2015:Q2

\begin{tabular}{|c|c|c|c|c|c|}
\hline \multirow{7}{*}{$\begin{array}{l}\text { A. Standard deviation of } \\
\text { variable relative to output }\end{array}$} & \multirow[b]{2}{*}{ Variable } & \multirow[b]{2}{*}{ Data } & \multirow[b]{2}{*}{ Benchmark } & \multicolumn{2}{|c|}{$\begin{array}{c}\text { Alternative } \\
\text { Model Specifications }\end{array}$} \\
\hline & & & & kNo OTJS I & o Fin. Shocks \\
\hline & Consumption & 1220.883 & 0.711 & 0.849 & 0.195 \\
\hline & Investment & 1224.247 & 3.985 & 3.493 & 3.617 \\
\hline & Unemployment & 1229.938 & 6.018 & 0.999 & 5.097 \\
\hline & $\mathrm{v} / \mathrm{u}$ ratio & 12219.749 & 13.530 & 4.569 & 10.923 \\
\hline & Labor income & 1221.409 & 1.844 & 2.893 & 0.706 \\
\hline \multirow{5}{*}{$\begin{array}{l}\text { B. Correlation of variable } \\
\text { with output }\end{array}$} & Consumption & 1220.905 & 0.505 & 0.652 & 0.497 \\
\hline & Investment & 1220.895 & 0.698 & 0.805 & 0.810 \\
\hline & Unemployment & $122-0.884$ & -0.770 & -0.501 & -0.869 \\
\hline & v/u ratio & 1220.892 & 0.584 & 0.356 & 0.948 \\
\hline & Labor income & 1220.776 & 0.491 & 0.403 & 0.936 \\
\hline \multirow{6}{*}{$\begin{array}{l}\text { C. Own-variable correlation } \\
\text { with data }\end{array}$} & Output & 1221.000 & 0.859 & 0.854 & 0.755 \\
\hline & Consumption & 1221.000 & 0.582 & 0.663 & 0.147 \\
\hline & Investment & 1221.000 & 0.415 & 0.418 & 0.570 \\
\hline & Unemployment & 1221.000 & 0.478 & 0.554 & 0.523 \\
\hline & v/u ratio & 1221.000 & 0.337 & 0.189 & 0.484 \\
\hline & Labor income & 1221.000 & 0.520 & 0.439 & 0.605 \\
\hline \multirow{2}{*}{$\begin{array}{l}\text { D. Summary } \\
\text { statistics }\end{array}$} & SAD & - & 15.122 & 30.910 & 19.329 \\
\hline & SSD & 16 & 56.205 & 315.411 & 104.533 \\
\hline
\end{tabular}

Notes: All data are in log deviations from steady state and obtained using an HP filter with smoothing parameter equal to 1600 .

Panel B of Table 1 shows correlations of variables with output. On this front and on net, all models perform fairly similarly. In particular, some models are somewhat better than others in matching certain correlations while at the same time somewhat worse than others in matching other correlations. Finally, Panel $\mathrm{C}$ of this Table shows the own-variable correlation with the data (hence why all the entries under the Data column are equal to 1). On net, the appraisal is similar to that with regards to Panel B, but in this case we do highlight the relatively low correlation of the No OTJS model's $v / u$ ratio with its empirical counterpart, as well as the relatively low correlation of the No Fin. Shocks model's consumption with its own empirical counterpart.

To provide a more comprehensive summary of relative model performance, Panel D of Table 1 shows the column-wise sum of absolute deviations (SAD) of each model relative to the Data column and the column-wise sum of squared deviations (SSD) of each model relative to the Data column. Note that the Benchmark model minimizes both of these measures substantially compared to the alternatives, by which we see additional evidence that of the proposed models the Benchmark is superior. 
Table 2: Additional statistics: 1990:Q2-2013:Q3 and 2001:Q1-2015:Q2

\begin{tabular}{llccccc}
\hline \hline & & & & \multicolumn{3}{c}{$\begin{array}{c}\text { Alternative } \\
\text { Model Specifications }\end{array}$} \\
\cline { 3 - 7 } & \multicolumn{1}{c}{ Variable } & \multicolumn{3}{c}{ Obs. Data } & BenchmarkNo OTJS No Fin. Shocks \\
\hline A. Standard deviation of & Net quits (DH) & 94 & 11.398 & 20.860 & 0.000 & 16.245 \\
variable relative to output & Net quits (JOLTS) & 58 & 15.352 & 22.631 & 0.000 & 17.567 \\
\hline B. Correlation of variable & Net quits (DH) & 94 & 0.776 & 0.355 & N/A & 0.786 \\
with output & Net quits (JOLTS) & 58 & 0.876 & 0.361 & N/A & 0.746 \\
\hline C. Own-variable correlation & Net quits (DH) & 94 & 1.000 & 0.322 & N/A & 0.375 \\
with data & Net quits (JOLTS) & 54 & 1.000 & 0.145 & N/A & 0.380 \\
\hline
\end{tabular}

Notes: All data are in log deviations from steady state and obtained using an HP filter with smoothing parameter equal to 1600. Net quits DH are constructed using data from Davis and Haltiwanger (2014) and data from the Current Population Survey; these data span 1990:Q2-2013:Q3. Net quits JOLTS are constructed using data from the Bureau of Labor Statistics' Job Openings and Labor Turnover Survey and the Current Population Survey; these data span 2001:Q1-2015:Q2.

In sum, the SAD and SSD measures imply that, on average, the Benchmark model performs best in matching a wide range of empirical statistics.

The variables whose statistics are reported in Table 1 are those for which we have data through the entire 1985:Q1-2015:Q2 period and, therefore, 122 observations. In contrast, recall that our measures of net quits are comparatively limited in data span. For the DH version of net quits we have only 94 observations ( 23 percent less compared to the observations on which Table 1 is constructed) comprising the period 1990:Q2-2013:Q3, and for the JOLTS measure of net quits we only have 58 observations (about 50 percent less compared to the observations on which Table 1 is constructed) comprising the period 2001:Q1-2015:Q2. With these caveats in mind, focus on Table 2, which reports similar statistics as in Table 1, but now focusing on net quits. Of course, the No OTJS model is a natural failure because in this model there are no job-to-job transitions. In turn, the Benchmark model performs quite well, although in comparison the No Fin. Shocks model performs somewhat better.

That said, we do not put too much weight on the statistics reported in Table 2 given the small amount of data they are based on compared to Table 1. Instead, we highlight once more the contour analysis in Figure 9, by which the Benchmark model highly outperformed the No Fin. Shocks model in 
matching the contraction in net quits amid the GFC. All told, we conclude that the statistical analysis presented in Tables 1 and 2 provide considerable support for the Benchmark model matching the data well in absolute terms, as well as compared to the No OTJS and No Fin. Shocks alternatives. (Our main conclusions continue to hold under alternative parameterizations for the benchmark model, as shown in the Appendix.)

\section{DRIVING FORCES BEHIND BENCHMARK RESULTS}

\section{A. Impulse Response Function Analysis}

To understand the driving forces behind the Benchmark model's results, Figures 10 and 11 show, respectively, the response of the Benchmark and No OTJS models to a 1-standard-deviation negative aggregate TFP shock and to a 1-standard-deviation negative financial shock. This analysis allows us to: illustrate the role of OTJ search in amplifying financial shocks; stress how the response to financial shocks differs from TFP shocks both qualitatively and quantitatively; and to show how these differential responses have important implications for wage, labor income, consumption, and unemployment dynamics.

\section{Negative Aggregate TFP Shock}

The response to this shock is in line with Krause and Lubik (2006, 2010). As such, we keep our discussion brief. In the presence of OTJ search, a negative TFP shock triggers a large contraction in vacancy postings that induces a rise in unemployment and a long-lived contraction in job-to-job flows from lower- to higher-paying jobs. As noted in Krause and Lubik (2006, 2010), the large reduction in the pool of on-the-job searchers puts upward pressure on market tightness among $H$ firms and leads to a sharper reduction in $H$ vacancies relative to a model without OTJ search (recall that job filling probabilities are decreasing in market tightness). The drop in OTJ search cascades down to $L$ firms, where the reduction in job-to-job transitions, all else equal, expands the measure of workers in these firms, which in turn pushes $L$ firms to reduce vacancies more aggressively relative to $H$ firms. 
All told, the response of unemployment is significantly amplified relative to an economy without OTJ search. $^{22}$
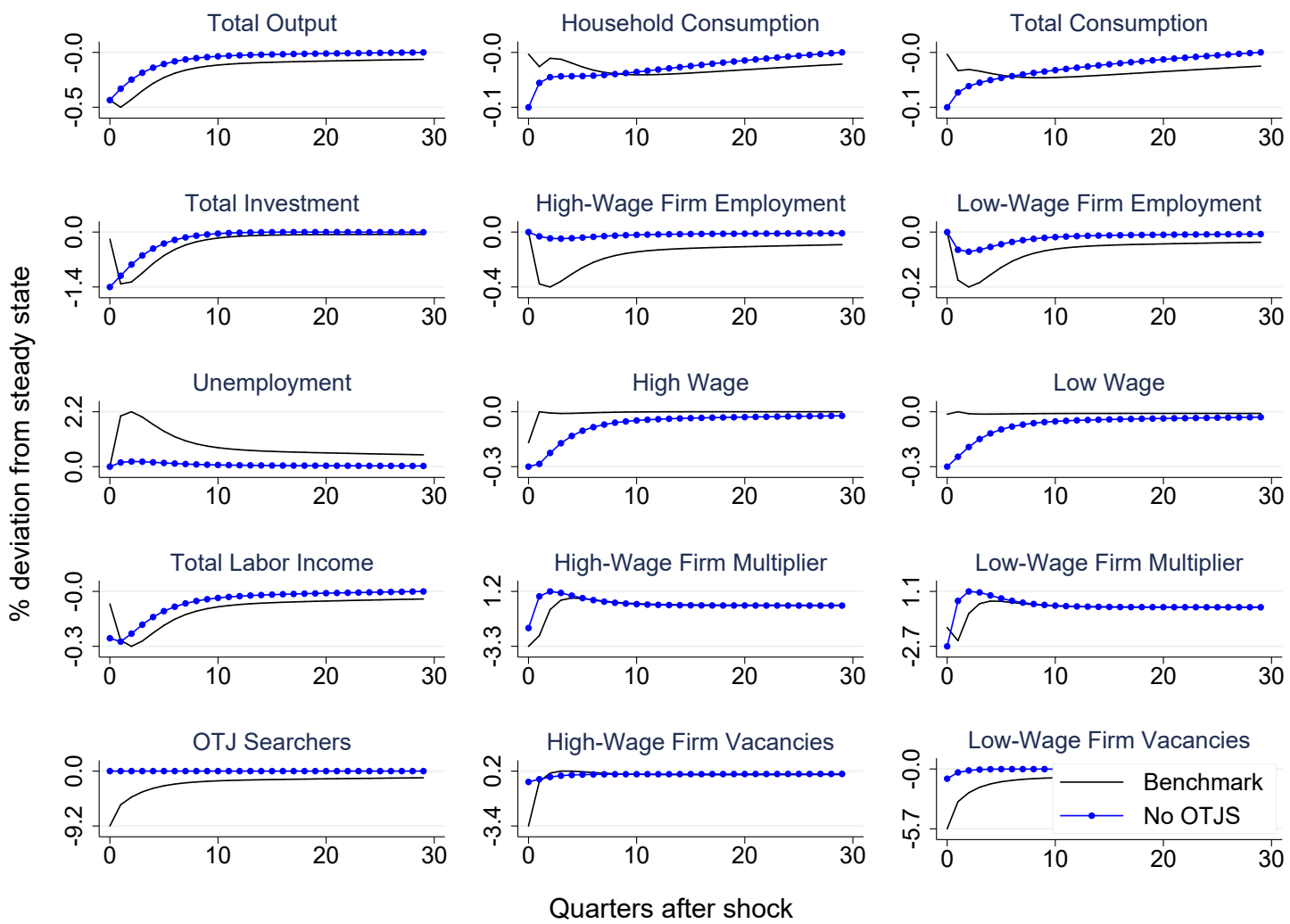

Figure 10: Impulse Response Functions to a 1-standard Deviation Negative TFP Shock.

The larger contraction in vacancies_-which traces back to OTJ search—reduces firms' borrowing, which puts larger downward pressure on firms' collateral multipliers. Since capital and workers are jointly used in production, these developments result in a fall in investment, which is more subdued with OTJ search since the downward adjustment in firms' collateral multipliers is larger. Importantly, though, OTJ search generates endogenous wage rigidities amid TFP shocks (on which we elaborate further below). These rigidities are responsible for the larger response in unemployment compared to a model without OTJ search but also lead to considerably smaller initial contractions in labor income, which ultimately explains the smaller reduction in consumption (conditional on a TFP shock) in the benchmark model.

\footnotetext{
${ }^{22}$ Per the analysis in Fujita and Ramey (2007), the empirical response of vacancies exhibits substantial propagation, which our model is unable to generate. This issue, however, is a well-known limitation of standard search-and-matching models that lies beyond the scope of this paper.
} 


\section{Negative Aggregate Financial Shock}

An adverse financial shock - a contraction in firms' borrowing capacity-tightens firms' collateral constraints, which in turn increases their collateral multipliers and adversely affects their incentive to hire workers. In other words, financial shocks by themselves contribute to more volatile recruiting and therefore more volatile outside options relative to an environment without these shocks. The fall in vacancies puts downward pressure on wages via changes in market tightness.
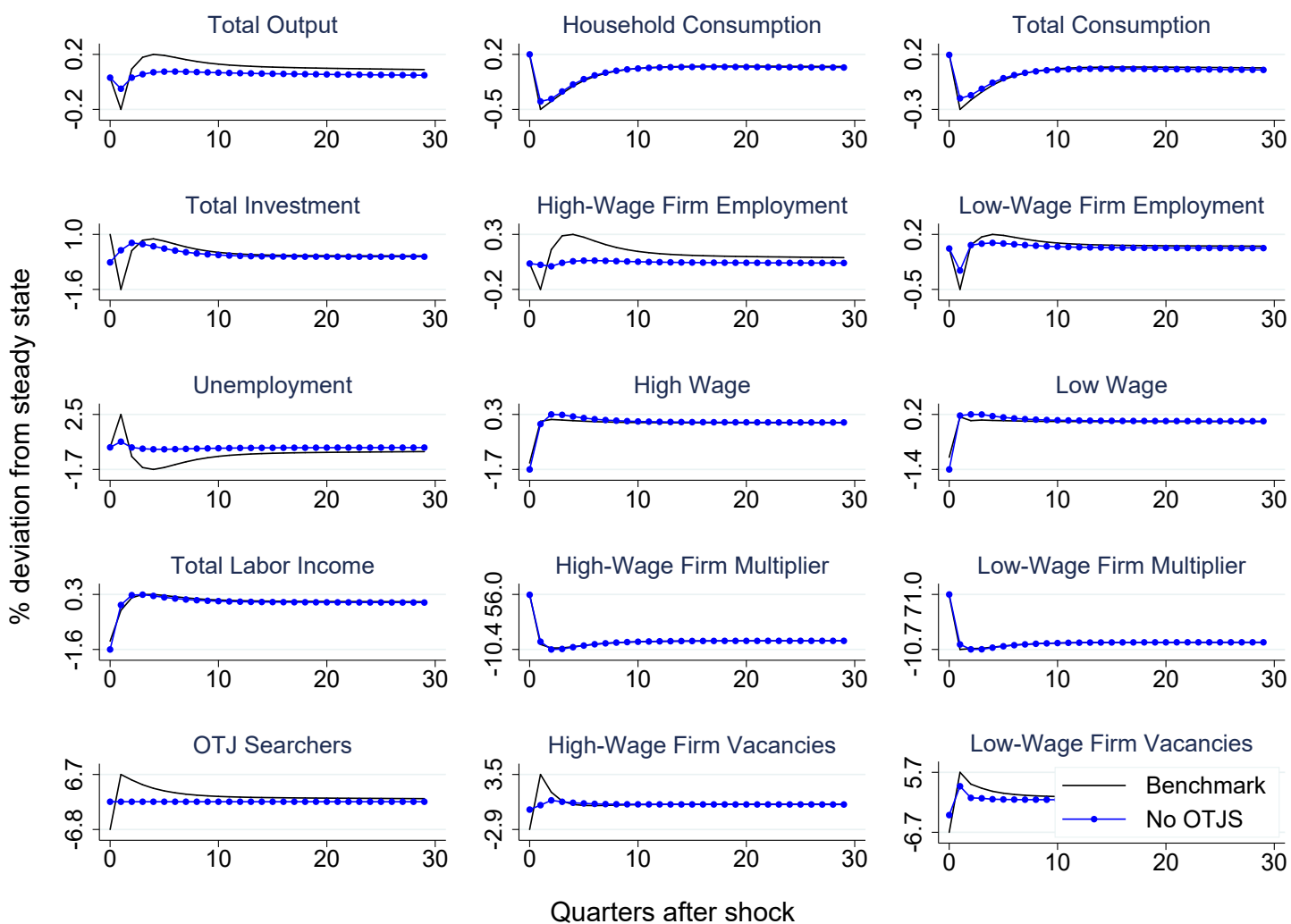

Figure 11: Impulse Response Functions to a 1-standard Deviation Negative Financial Shock.

From the workers' perspective, the value of a low-wage job decreases not only because of the sharp contraction in that sector's wages, but also because the value of OTJ search declines as well (jobto-job flows are an alternative avenue through which workers can access high-wage jobs, which are also subject to a contraction in wages). OTJ searchers reduce their search intensity in $H$ firms, thereby causing a further decline in vacancies that would otherwise not take place if OTJ search were not present. As such, employment in $L$ firms (as well as $H$ firms) declines by more than in the absence of OTJ search, resulting in an amplified (yet short-lived) response in unemployment. Moreover, adverse financial shocks have a large negative effect on subsequent investment (that is, 
investment after the period of the shock), which also contributes to a much stronger change in the incentive to post vacancies. This ultimately leads to sharper unemployment fluctuations with OTJ search.

Importantly, while the amplification effect induced by OTJ search seemingly operates through the same channels described for TFP shocks (i.e., a fall in OTJ searchers puts upward pressure on $H$ firms' market tightness, leading to a sharper contraction in vacancies that cascades down to $L$ firms, thereby further adversely affecting vacancy creation), the amplification of unemployment is not accompanied by endogenously rigid wages, as was the case under TFP shocks. This absence of wage rigidity is the fundamental driver in generating non-negligible quantitative differences between the economy's response to TFP and financial shocks. In particular, the differential quantitative response of wages under these shocks can be traced back to the differential response of firms' collateral multipliers (which proxy for financial conditions). Given the seemingly similar nature of the amplification channels with OTJ search, why is the interaction between OTJ search and financial shocks so critical for matching the data, as shown earlier? While OTJ search generates enough volatility in unemployment by inducing relatively rigid wages, financial shocks offset that wage rigidity via sharp movements in financial stress (as captured by firms' collateral multipliers), which feed into firms' future value of employment relationships, and therefore wages. Ultimately, these shocks allow high unemployment volatility (rooted in OTJ search) and high labor income (wage) and consumption volatility (rooted in financial disturbances) to coexist. We discuss this issue more formally in the next section.

Before proceeding, some additional details regarding financial shocks are worth noting. The brief initial increase in consumption is consistent with the findings in Jermann and Quadrini (2012) and others. For example, as explained in Garín (2015), a contraction in firms' ability to borrow reduces the demand for borrowed funds, putting downward pressure on interest rates and reducing households' incentive to save. This contributes to the initial and short-lived expansion in consumption in the period where the shock hits. Consumption subsequently contracts rapidly, as would be expected from a deterioration in financial conditions. ${ }^{23}$ Note, though, that if an adverse financial shock is accompanied by a fall in exogenous aggregate productivity, household consumption would in fact contract, which is exactly what happened at the onset of the GFC: a simultaneous fall in TFP and borrowing capacity (recall Figure 1).

\footnotetext{
${ }^{23}$ If households were to face financial frictions of their own, which we abstract from, then a negative financial shock would likely lead to a fall in consumption on impact.
} 
In contrast to Jermann and Quadrini (2012) and Garín (2015), as shown in Figure 11 investment increases on impact of the negative financial shock before subsequently falling below trend, as should be expected. This result traces back to the two-sector nature of our economic environment, the presence of job-to-job flows, and the differences in the relative adjustment of sectoral wages (and therefore sectoral profits) to shocks. Looking at investment for each firm separately in our model (not shown for brevity) reveals that, while investment among $L$ firms does contract after the shock, investment among $H$ firms expands on impact. Intuitively, $H$-firm investment is due to the fact that firm- $H$ wages exhibit a sharper downward adjustment relative to firm- $L$ wages as a result of the reduction in job-to-job flows, which all else equal boosts firm profits, reduces the marginal cost of investing relative to $L$ firms, and therefore boosts investment among $H$ firms. This response ultimately drives the dynamics of total investment. Given that most of the literature has considered one-sector models, this particular result had not surfaced in previous studies.

\section{B. Wages and Consumption: TFP v. Financial Shocks}

To understand the differential response of wages under the two shocks more clearly, without loss of generality, consider firm $H$ 's decision over borrowed funds, which can be rewritten as $R_{t}^{-1}-$ $\lambda_{H, t}=\mathbb{E}_{t} \Xi_{t+1 \mid t}^{H}$. To fix ideas, first assume that $R$ is constant. Then, an increase in firm $H$ 's collateral multiplier $\lambda_{H}$ reduces firm $H$ 's stochastic discount factor $\Xi_{t+1 \mid t}^{H}$. In particular, a very sharp rise in $\lambda_{H}$ such as those generated by our financial shocks lead to sharp declines in $\Xi_{t+1 \mid t}^{H} \cdot{ }^{24}$ In turn, the latter directly affects $H$ firms' future incentives to post vacancies and to invest by lowering the value of future capital and employment relationships via a sharply lower stochastic discount factor. How do changes in $\lambda_{H}$ feed into wage dynamics? For expositional simplicity, assume that the wage bill is not part of the firm's collateral constraint. ${ }^{25}$ Then, firm H's wage can be written as:

$$
\begin{aligned}
w_{H, t}= & (1-\phi) \chi-(1-\phi) \mathbb{E}_{t} \Xi_{t+1 \mid t}\left[(1-\rho)\left(1-f_{H, t}\right)\left(\mathbf{W}_{H, t+1}-\mathbf{U}_{H, t+1}\right)\right] \\
& +\phi\left[p_{H, t} z_{t} F_{n_{H, t}}+(1-\rho) \mathbb{E}_{t} \Xi_{t+1 \mid t}^{H} \mathbf{J}_{H, t+1}\right] .
\end{aligned}
$$

\footnotetext{
${ }^{24}$ This would still be the case even when $R$ fluctuates since the cyclical movements in the collateral multiplier tend to be quantitatively much larger than the movements in $R$.

${ }^{25}$ Having the wage bill in the collateral constraint would introduce an additional channel through which changes in the collateral multiplier affects wages, mainly by changing the effective bargaining power of workers coming from changes in $\lambda_{H}$. As shown in the Appendix, where we shut down the wage bill in the collateral constraint (that is, when $\eta_{w}=0$ ), this additional channel is only second order to the one just discussed.
} 
First, note that all else equal a lower job-finding probability $f_{H}$ puts downward pressure on wages. Financial frictions affect wages via firms' collateral multipliers, and therefore via $\Xi_{t+1 \mid t}^{H}$. Then, an adverse financial shock increases the firm's collateral multiplier and induces a sharp contraction in $\Xi_{t+1 \mid t}^{H}$, thereby exerting substantial downward pressure on wages by reducing the value of future employment relationships, $\mathbb{E}_{t} \Xi_{t+1 \mid t}^{H} \mathbf{J}_{H, t+1}$. Conversely, a negative TFP shock relaxes firms' collateral constraints by reducing firms' demand for borrowed funds for production, reduces the firm's collateral multiplier, thereby exerting upward pressure on wages via an increase in $\Xi_{t+1 \mid t}^{H}$. As such, even if both shocks generate sharp contractions in vacancies as a result of the OTJ search mechanism, the contrasting behavior of firms' collateral multiplier between shocks generates sharp wage dynamics in the case of financial shocks, but mild movements in wages in the case of TFP shocks. In turn, this leads to larger fluctuations in labor income and ultimately consumption amid financial shocks, but to small movements in these variables under TFP shocks in the presence of OTJ search. All told, financial shocks play a key role in generating larger wage movements, which ultimately feed into labor income and consumption dynamics by affecting firms' valuation of the future and therefore their incentives to hire and invest.

Of note, the interaction between OTJ search and financial shocks magnifies the response of wages over the business cycle by generating larger contractions in vacancies (where the latter affects wages via market tightness, which is embodied in $f_{H}$ ) after a downturn relative to a model without OTJ search, and also by generating sharp movements in firms' value of future employment relationships, $\mathbb{E}_{t} \Xi_{t+1 \mid t}^{H} \mathbf{J}_{H, t+1}$. More importantly, the presence of larger wage movements does not imply that the rise in unemployment is more subdued under financial shocks. This result is subtle yet critical in light of existing literature on wage rigidities and unemployment dynamics. Our benchmark modelwith both OTJ search and financial shocks - can simultaneously generate non-negligible and more factual fluctuations in wages, labor income, and consumption, as well as high unemployment volatility. That is, considerable wage rigidities (whether endogenous or exogenous)—rigidities that, while contributing to higher unemployment volatility, prevent standard models from replicating the volatility of labor income and consumption in the data, especially during recessions - are not necessary to produce high unemployment volatility in the presence of both financial shocks and job-to-job flows.

Finally, we note that while the initial contraction in OTJ search intensity-which is reflected in the behavior of OTJ searchers-is similar for TFP and financial shocks on impact, the ensuing recovery differs considerably despite the fact that our estimated stochastic processes suggest that financial 
shocks are somewhat more persistent than TFP shocks (see Figures 10 and 11). After a negative TFP shock, the contraction in OTJ search intensity is considerably persistent. In contrast, after a negative financial shock, OTJ search intensity contracts on impact but quickly rebounds and overshoots its steady-state level for several quarters before returning to trend. In turn, this development explains why recessions induced by financial disruptions generate expansions in unemployment that are sharp yet shorter-lived relative to recessions induced by contractions in TFP. Moreover, this result also hints at a plausible underlying reason behind the limitations of models with financial frictions in explaining sluggish recoveries after financial shocks.

All told, households' wages and total labor income exhibit relatively large contractions compared to output in response to adverse financial shocks. These dynamics suggest that financial shocks can contribute to higher consumption volatility that is closer to the data, which, as implied by inspection of Tables 1 and 2, is indeed the case. In turn, OTJ search produces sharp movements in unemployment and vacancies, even in the presence of volatile wages and labor income (where the latter are a result of financial disturbances). That is, high wage and unemployment volatility can coexist, and indeed this important and empirically-factual coexistence contributes to a better overall fit of the Benchmark model with the data, both before and amid the GFC.

\section{CONCLUSIONS}

Some well-known stylized facts of U.S. recessions are: increases in the unemployment rate; decreases in output, consumption, investment, labor income, job-to-job flows; and higher credit tightness. Amid the Global Financial Crisis (GFC), the quantitative magnitude of these facts was amplified. In particular, credit tightness skyrocketed while job-to-job flows plummeted (i.e., the labor upgrading opportunities were severely impaired). The interaction of on-the-job (OTJ) search with total factor productivity (TFP) shocks is well understood. In contrast, the aggregate implications of OTJ search and financial shocks are lesser known.

In this paper, we develop a business cycle model with on-the-job (OTJ) search, collateral constraints in the production sector, and financial shocks. Following the approach by Jermann and Quadrini (2012), we construct TFP time series and model-based time series for financial conditions. Purging these series of interaction effects and feeding these series into the model, we show that the interaction between financial disruptions, TFP, and job-to-job flows can play a substantial role in driving 
the behavior of unemployment and key macro aggregates both in the wake of the GFC and in prior years. In particular, under standard calibrations financial shocks offset the endogenous wage rigidities inherent to OTJ search, thereby allowing high labor income and consumption volatility to coexist along with sharp unemployment fluctuations, as in the data. These are features of the data that existing models cannot replicate in a comprehensive way.

While the model is exceedingly successful in capturing the cyclical dynamics of labor and aggregate variables through the GFC, it faces limitations in replicating the sluggishness of the recovery phase, which is a topic that remains of particular relevance and suggests that, on their own, within our framework neither TFP nor financial shocks can explain the slow recovery process in the aftermath of the crisis. Within the context of our analysis, this limitation is unsurprising, though, as we abstract from income effects stemming from the steep decline in asset prices, including housing, that characterized the GFC as well as uncertainty and the slow process of balance-sheet repairs. Extending our framework to incorporate these additional features is a promising avenue for future research directed at understanding the slow recovery from the GFC.

\section{REFERENCES}

Acemoglu, Daron. 2001. "Good Versus Bad Jobs,” Journal of Labor Economics, Vol. 19(1), pp. 1-21.

Albrecht, James, and Susan Vroman. 2002. "A Matching Model with Endogenous Skill Requirements," International Economic Review, Vol. 43(1), pp. 283-305.

Arseneau, David M., and Sanjay K. Chugh. 2012. "Tax smoothing in frictional labor markets." Journal of Political Economy, Vol. 120(5), pp. 926-985.

Arseneau, David M., and Brendan Epstein. 2014. "The Welfare Costs of Skill-Mismatch Employment," Finance and Economics Discussion Series Paper 2014-42, Board of Governors of the Federal Reserve System.

Barlevy, Gadi. 2002. "The Sullying Effect of Recessions," The Review of Economic Studies, Vol. 69(1), pp. 65-96.

Barnichon, Regis, and Yanos Zylbergberg. 2014. "Under-Employment and the Trickle-Down of Unemployment," mimeo.

Boeri, Tito, Pietro Garibaldi, and Espen R. Moen. 2015. "Financial Frictions, Financial Shocks and Unemployment Volatility," mimeo. 
Buera, Fransisco J., Roberto N. Fattal Jaef, and Yongseok Shin. 2015. “Anatomy of a Credit Crunch: From Capital to Labor Markets," Review of Economic Dynamics, Vol. 18(1), pp. 101117.

Carlstrom, Charles T., and Timothy S. Fuerst. 1997. "Agency Costs, Net Worth, and Business Fluctuations: A Computable General Equilibrium Analysis," American Economic Review, Vol. 87(5), pp. 893-910.

Chassamboulli, Andri. 2011. "Cyclical Upgrading of Labor and Employment Differences Across Skill Groups,” The B.E. Journal of Macroeconomics, Vol. 11(1), pp. 1935-1690.

Chassamboulli, Andri. 2013. "Labour-Market Volatility in a Matching Model with Worker Heterogeneity and Endogenous Separations," Labour Economics, Vol. 24, pp. 217-229.

Chugh, Sanjay K. 2013. "Costly External Finance and Labor Market Dynamics," Journal of Economic Dynamics and Control, Vol. 37(12), pp. 2882-2912.

Davis, Steven J., and John Haltiwanger. 2014. "Labor Market Fluidity and Economic Performance," Federal Reserve Bank of Kansas City Jackson Hole 2014 Economic Policy Symposium.

Dolado, Juan J., Marcel Jansen, and Juan F. Jimeno. 2009. “On-the-Job Search in a Matching Model with Heterogeneous Jobs and Workers," Economic Journal, Vol. 119(534), pp. 200228.

Duygan-Bump, Burcu, Alexey Levkov, and Judit Montoriol-Garriga. 2014. "Financing Constraints and Unemployment: Evidence from the Great Recession," Finance and Economics Discussion Series 2014-92, Board of Governors of the Federal Reserve System.

Eckstein, Zvi, Ofer Setty, and David Weiss. 2015. "Financial Risk and Unemployment," mimeo.

Elsby, Michael W.L., Ryan Michaels, and Gary Solon. 2009. "The Ins and Outs of Cyclical Unemployment," American Economic Journal: Macroeconomics, Vol. 1(1), pp. 84-110.

Epstein, Brendan. 2012. "Heterogeneous Workers, Optimal Job Seeking, and Aggregate Labor Market Dynamics," International Finance Discussion Papers Number 1053, Board of Governors of the Federal Reserve System.

Fallick, Bruce, and Charles A. Fleischman. 2004. "Employer-to-Employer Flows in the U.S. Labor Market: The Complete Picture of Gross Worker Flows," Finance and Economics Discussion Series Papers 2004-34, Board of Governors of the Federal Reserve System.

Fujita, Shigeru. 2014. "On the Causes of Declines in the Labor Force Participation Rate," Research Rap Special Report, Federal Reserve Bank of Philadelphia, 6.

Fujita, Shigeru, and Garey Ramey. 2007. "Job Matching and Propagation,” Journal of Economic Dynamics and Control, Vol. 31(11), pp. 3671-3698. 
Garín, Julio. 2015. "Borrowing Constraints, Collateral Fluctuations, and the Labor Market," Journal of Economic Dynamics and Control, Vol. 57(C), pp. 112-130.

Gautier, Pieter A. 2002. "Unemployment and Search Externalities in a Model with Heterogeneous Jobs and Workers,” Economica, Vol. 69(273), pp. 21-40.

Gertler, Mark, Chris Huckfeldt, and Antonella Trigari. 2014. "Unemployment Fluctuations, Match Quality, and The Wage Cyclicality of New Hires," mimeo.

Gilchrist, Simon, and Egon Zakrajšek. 2012. "Credit Spreads and Business Cycle Fluctuations," American Economic Review, Vol. 102(4), pp. 1692-1720.

Gu, Weishi. 2014. "The Cost of Benefits, Financial Conditions, and Employment Dynamics in Recent U.S. Recoveries," mimeo.

Hagedorn, Marcus, and Iourii Manovskii. 2008. "The Cyclical Behavior of Equilibrium Unemployment and Vacancies Revisited," The American Economic Review, Vol. 98(4), pp. 16921706.

Hall, Robert E., and Paul R. Milgrom. 2008. "The Limited Influence of Unemployment on the Wage Bargain,” American Economic Review, Vol. 98(4), pp. 1653-1674.

Iacoviello, Matteo. 2015. "Financial Business Cycles," Review of Economic Dynamics, Vol. 18(1), pp. 140-163.

Jermann, Urban, and Vincenzo Quadrini. 2012. "Macroeconomic Effects of Financial Shocks," American Economic Review, Vol. 102(1), pp. 238-271.

Karabarbounis, Loukas, and Brent Neiman. 2014. "The Global Decline in the Labor Share," Quarterly Journal of Economics, Vol. 129(1), pp. 61-103.

Kiyotaki, Nobuhiro, and John Moore. 1997. “Credit Cycles," Journal of Political Economy, Vol. 105(2), pp. 211-248.

Krause, Michael U., and Thomas A. Lubik. 2006. "The Cyclical Upgrading of Labor and Onthe-Job Search," Labour Economics, Vol. 13(4), pp. 459-477.

Krause, Michael U., and Thomas A. Lubik. 2010. "On-the-Job Search and the Cyclical Dynamics of the Labor Market," Federal Reserve Bank of Richmond Working Paper Series WP 10-12.

Liu, Zheng, Pengfei Wang, and Tao Zha. 2013. "Land-Price Dynamics and Macroeconomic Fluctuations," Econometrica, Vol. 81(3), pp. 1147-1184.

Lopez, Jose Ignacio, and Virginia Olivella. 2014. "Financial Shocks and the Cyclical Behavior of Skilled and Unskilled Unemployment," Document de Travail No. 496, Banque de France.

McLaughlin, Kenneth J., and Mark Bils. 2001. "Interindustry Mobility and the Cyclical Upgrading of Labor," Journal of Labor Economics, Vol. 19(1), pp. 94-135. 
Mehrotra, Neil, and Dmitriy Sergeyev. 2012. "Sectoral Shocks, the Beveridge Curve and Monetary Policy," mimeo.

Mehrotra, Neil R., and Dmitriy Sergeyev. 2015. "Financial Shocks and Job Flows," mimeo.

Menzio, Guido, and Shouyong Shi. 2010. "Directed Search on the Job, Heterogeneity, and Aggregate Fluctuations,” American Economic Review, Vol. 100(2), pp. 327-332.

Menzio, Guido, and Shouyong Shi. 2011. "Efficient Search on the Job and the Business Cycle," Journal of Political Economy, Vol. 119(3), pp. 468-510.

Merz, Monika. 1995. "Search in the Labor Market and the Real Business Cycle," Journal of Monetary Economics, Vol. 36(2), pp. 269-300.

Monacelli, Tomasso, Vincenzo Quadrini, and Antonella Trigari. 2012. "Financial Markets and Unemployment," Marshall Research Paper Series Working Paper FBE 01.13, University of Southern California Marshall School of Business.

Moscarini, Giuseppe, and Fabien Postel-Vinay. 2016. "Did the Job Ladder Fail After the Great Recession,” Journal of Labor Economics, Vol. 34(S1, Part 2), pp. 55-93

Nagypál, Eva. 2005. “On the Extent of Job-to-Job Transitions,” mimeo.

Nagypál, Eva. 2007. "Labor-Market Fluctuations and On-the-Job Search,” mimeo.

Nagypál, Eva. 2008. "Worker Reallocation Over the Business Cycle: The Importance of Employer-to-Employer Transitions," mimeo.

Petrongolo, Barbara, and Christopher A. Pissarides. 2001. "Looking into the Black Box: A Survey of the Matching Function," Journal of Economic Literature, Vol. 39(2), pp. 390-431.

Petrosky-Nadeau, Nicolas. 2014. "Credit, Vacancies and Unemployment Fluctuations," Review of Economic Dynamics, Vol. 17(2), pp. 191-205.

Pissarides, Christopher A. 1994. "Search Unemployment with On-the-Job Search," Review of Economic Studies, Vol. 61(3), pp. 457-475.

Pissarides, Christopher A. 2000. Equilibrium Unemployment Theory. MIT press.

Ravenna, Federico, and Carl E. Walsh. 2012. "Screening and Labor Market Flows in a Model with Heterogeneous Workers," Journal of Money, Credit and Banking, Vol. 44(2), pp. 31-71.

Ravenna, Federico, and Carl E. Walsh. 2014. "Slow Recoveries, Worker Heterogeneity, and the Zero Lower Bound," mimeo.

Schaal, Edouard. 2015. "Uncertainty and Unemployment," mimeo.

Shimer, Robert. 2005. "The Cyclical Behavior of Equilibrium Unemployment and Vacancies," American Economic Review, Vol. 95(1), pp. 25-49. 
Shimer, Robert. 2006. "On-the-Job Search and Strategic Bargaining," European Economic Review, Vol. 50(4), pp. 811-830.

Shimer, Robert. 2014. "Reassessing the ins and outs of unemployment." Review of Economic Dynamics, Vol. 15(2), pp. 127-148.

Tasci, Murat. 2007. "On-the-Job Search and Labor Market Reallocation," Federal Reserve Bank of Cleveland Working Paper 07-25, Federal Reserve Bank of Cleveland.

Zanetti, Francesco. 2015. "Financial Shocks and Labor Market Fluctuations," mimeo. 